\title{
EPC/HPSG evidence-based guidelines for the management of pediatric pancreatitis
}

\author{
Andrea Párniczky ${ }^{\text {a, b }}$, Maisam Abu-El-Haija ${ }^{c}$, Sohail Husain ${ }^{\mathrm{d}}$, Mark Lowe ${ }^{\mathrm{e}}$, \\ Grzegorz Oracz ${ }^{\mathrm{f}}$, Miklós Sahin-Tóth ${ }^{\mathrm{g}}$, Flóra K. Szabó ${ }^{\mathrm{h}}$, Aliye Uc ${ }^{\mathrm{i}}$, Michael Wilschanski ${ }^{\mathrm{j}}$, \\ Heiko Witt ${ }^{k}$, László Czakó ${ }^{1}$, Tassos Grammatikopoulos ${ }^{\mathrm{m}, \mathrm{n}}$, Ib Christian Rasmussen ${ }^{\circ}$, \\ Robert Sutton ${ }^{\text {p, q, }}$, Péter Hegyi ${ }^{\text {b, }, \text {, * }}$
}

a Heim Pál Children's Hospital, Budapest, Hungary

${ }^{\mathrm{b}}$ Institute for Translational Medicine, University of Pécs, Pécs, Hungary

${ }^{c}$ Division of Gastroenterology, Hepatology and Nutrition, Cincinnati Children's Hospital Medical Center, Cincinnati, OH, USA

d Department of Pediatrics, Children's Hospital of Pittsburgh of University of Pittsburgh Medical Center, Pittsburgh, PA, USA

e Department of Pediatrics, Washington University School of Medicine, St. Louis, MO, USA

${ }^{\mathrm{f}}$ Department of Gastroenterology, Hepatology, Feeding Disorders and Pediatrics, The Children's Memorial Health Institute, Warsaw, Poland

${ }^{g}$ Department of Molecular and Cell Biology, Center for Exocrine Disorders, Boston University Henry M. Goldman School of Dental Medicine, Boston, MA, USA

${ }^{\mathrm{h}}$ Division of Gastroenterology and Nutrition, Children's Hospital of Richmond, Virginia Commonwealth University, Richmond, VA, USA

${ }^{\mathrm{i}}$ Division of Pediatric Gastroenterology, Stead Family Department of Pediatrics, University of Iowa Carver College of Medicine, Iowa City, IA, USA

j Pediatric Gastroenterology Unit, Hadassah Hebrew University Hospital, Jerusalem, Israel

${ }^{\mathrm{k}}$ Else Kröner-Fresenius-Zentrum für Ernährungsmedizin, Paediatric Nutritional Medicine, Technische Universität München, Freising, Germany

${ }^{1}$ First Department of Medicine, University of Szeged, Szeged, Hungary

m Paediatric Liver, GI \& Nutrition Centre, King's College Hospital, London, United Kingdom

${ }^{\mathrm{n}}$ Institute of Liver Studies, Division of Transplantation Immunology and Mucosal Biology, King's College London, London, United Kingdom

${ }^{\circ}$ Department of Surgery, Uppsala University Hospital, Uppsala, Sweden

p Department of Molecular and Clinical Cancer Medicine, Institute of Translational Medicine, University of Liverpool, Liverpool, UK

${ }^{\mathrm{q}}$ Liverpool Pancreatitis Research Group, Royal Liverpool University Hospital, Institute of Translational Medicine, University of Liverpool, Liverpool, UK

\section{A R T I C L E I N F O}

Article history:

Received 20 October 2017

Received in revised form

1 January 2018

Accepted 4 January 2018

Available online 4 January 2018

Keywords:

Pediatric pancreatitis

Evidence-based management guidelines

Acute pancreatitis

Chronic pancreatitis

Recurrent acute pancreatitis

\section{A B S T R A C T}

Background: Pediatric pancreatitis is an underdiagnosed disease with variable etiology. In the past 10-15 years the incidence of pediatric pancreatitis has increased, it is now 3.6-13.3 cases per 100,000 children. Up-to-date evidence based management guidelines are lacking for the pediatric pancreatitis. The European Pancreatic Club, in collaboration with the Hungarian Pancreatic Study Group organized a consensus guideline meeting on the diagnosis and management of pancreatitis in the pediatric population.

Methods: Pediatric Pancreatitis was divided into three main clinical categories: acute pancreatitis, acute recurrent pancreatitis and chronic pancreatitis. Fifteen relevant topics (acute pancreatitis: diagnosis; etiology; prognosis; imaging; complications; therapy; biliary tract management; acute recurrent pancreatitis: diagnosis; chronic pancreatitis: diagnosis, etiology, treatment, imaging, intervention, pain, complications; enzyme replacement) were defined. Ten experts from the USA and Europe reviewed and summarized the available literature. Evidence was classified according to the GRADE classification system.

Results: Within fifteen topics, forty-seven relevant clinical questions were defined. The draft of the updated guideline was presented and discussed at the consensus meeting held during the 49th Meeting of European Pancreatic Club, in Budapest, on July 1, 2017.

Abbreviations: AP, acute pancreatitis; APA, American Pancreatic Association; CFTR, cystic fibrosis transmembrane regulator; CPA1, Carboxypeptidase A1; CP, chronic

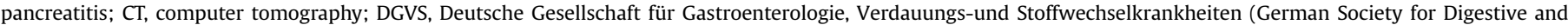

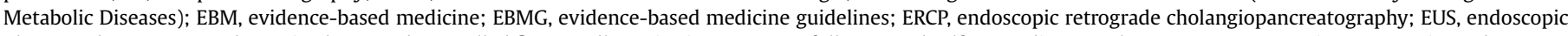

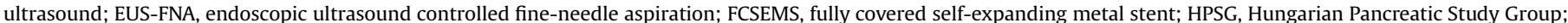

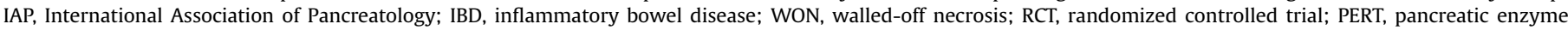
replacement therapy; EPI, exocrine pancreatic insufficiency.

* Corresponding author. Institute for Translational Medicine, 12 Szigeti Street, Pécs, H-7624, Hungary.

E-mail address: hegyi2009@gmail.com (P. Hegyi). 
Conclusions: These evidence-based guidelines provides the current state of the art of the diagnosis and management of pediatric pancreatitis.

๑) 2018 IAP and EPC. Published by Elsevier B.V. This is an open access article under the CC BY-NC-ND license (http://creativecommons.org/licenses/by-nc-nd/4.0/).

\section{Introduction}

Inflammation of the pancreas in children is rarely diagnosed and the etiologies are diverse. Pediatric acute and acute recurrent pancreatitis are significantly more common than it was previously presumed and depending on the nature of the disease, it can lead to chronic pancreatitis (CP). The most common causes are trauma, structural anomalies, infection, systemic disease, medication or biliary disease and genetic etiologies. In most cases, pediatric pancreatitis (PP) is mild with good prognosis. In the last 10-15 years, the incidence of pediatric pancreatitis has been on the rise. The incidence based on international data is 3.6-13.3 cases per 100,000 children, while data regarding CP are lacking [1]. There is great variability in the severity, clinical progression and late complications of the disease.

Having a significant effect on the life of the children and parents $P P$ requires up-to-date and evidence -based treatment approaches. Owing to the initiative of the International Association of Pancreatology (IAP) and the American Pancreatic Association (APA), with international and multidisciplinary collaboration, a modern and evidence-based treatment guideline for acute pancreatitis (AP) in adults were drafted in 2012, and published in 2013. In 2012, the German Society of Digestive and Metabolic Diseases (DGVS) also published a similar guideline for $\mathrm{CP}$ [2]. The International Study Group of Pediatric Pancreatitis: In Search for a Cure (INSPPIRE) was founded in 2010 described the first ever pediatric definition of AP, ARP and CP [3] and developed consensus guidelines for evaluation of pediatric ARP, CP and its risk factors [4-6]. Hungarian Pancreatic Study Group (HPSG) developed the first evidence-based medicine (EBM) management guideline in PP in 2014 and published it in 2015 in Hungarian [7]. There were plenty of requests from pediatricians from all over the world to make it available in English, therefore, the European Pancreatic Club (EPC), in collaboration with the Hungarian Pancreatic Study Group (HPSG) organized a consensus guideline meeting to generate a report on the diagnosis and management of pediatric pancreatitis.

\section{Objective}

The aim of EPC and HPSG is to establish evidence-based guidelines for the diagnosis and management of PP (PP-EBM) by thoroughly reviewing, summarizing and discussing the international studies and existing adult guidelines, expanding them if necessary and in case of agreement, implementing them in the world. Our fundamental goal is to improve patient management, assist medical providers make clinical decisions and to help the financial regulatory authorities establish the grounds for an EBM based patient-care system.

\section{Methods}

Preparation process of the guideline

1) Two of the investigators translated the 2015 HPSG PP-EBM into English.

2) Ten investigators (experts from pediatric pancreatitis) extended, modified and reviewed the questions and answers and added their own propositions, which were included in the first draft of the revised PP-EBM.

3) The consensus meeting was held on July 1, 2017 in Budapest as part of the 49th European Pancreatic Club Meeting 2017. The consensus meeting was open for all delegates who attended the conference. In order to get the highest quality PP-EBM, four key multidisciplinary experts (in pediatrics, endoscopy, surgery and gastroenterology) were invited. Attendees were allowed to suggest modifications to the draft recommendations. All attendees voted on the strength of the consensus via a secret balloting system. The event was recorded for documentation purposes.

4) The members of the consensus panel received the finished PPEBM for another review.

\section{Classification of the evidence}

The classification of the evidence was based on the GRADE Working Group internationally accepted system, which was established in 2011 (www.gradeworkinggroup.org). These criteria are presented in Table 1.

\section{Degree of consensus}

Recommendation: the strength of the GRADE recommendation ( 1 =strong, 2 =weak), the quality of the evidence $(A=$ high, $\mathrm{B}=$ moderate, $\mathrm{C}=$ low), and the strength of the international experts' consensus (strong/weak) are indicated.

The participating members determined the strength of the consensus by voting yes or no. Degrees of consensus were as follows: 95\% or more 'yes' votes were considered 'full agreement'; at least $70 \%$ 'yes' votes indicated 'strong agreement', and more than $50 \%$ 'yes' votes were regarded as 'weak agreement'. (See Table 2).

\section{Acute pediatric pancreatitis (PP)}

\section{AP-I. Diagnosis and definition}

AP-I.1. A diagnosis of AP is achieved by meeting at least 2 of the following 3 criteria: 1) abdominal pain; 2) serum lipase or serum amylase level at least three times greater than the upper limit of normal; 3) characteristic findings of AP with imaging methods. (GRADE 1/B, full agreement)

AP-I.2. Diffuse, epigastric, persistent or minimally easing abdominal pain suggests AP in childhood. (GRADE $1 / C$, full agreement)

AP-I.3. In children, especially in infants and in toddlers, vomiting, irritability, abdominal distension may suggest AP. (GRADE 1/B, full agreement)

AP-I.4. Measurement of serum amylase and/or lipase among the routine laboratory tests is recommended in presence of abdominal pain. (GRADE 1/C, full agreement)

\section{AP-II. Etiology}

AP-II. Etiological factors that should be considered after the 
Table 1

Grading tutorial (www.uptodate.com/home/grading-tutorial).

\begin{tabular}{|c|c|c|c|}
\hline $\begin{array}{l}\text { Grade of } \\
\text { Recommendation }\end{array}$ & Clarity of risk/benefit & Quality of supporting evidence & Implications \\
\hline $\begin{array}{l}\text { 1A. } \\
\text { Strong } \\
\text { recommendation. } \\
\text { High quality } \\
\text { evidence. }\end{array}$ & $\begin{array}{l}\text { Benefits clearly outweigh risks and } \\
\text { burdens, or vice versa. }\end{array}$ & $\begin{array}{l}\text { Consistent evidence from well-performed randomized, } \\
\text { controlled trials or overwhelming evidence of some other } \\
\text { form. Further research is unlikely to change our confidence in } \\
\text { the estimate of benefit and risk. }\end{array}$ & $\begin{array}{l}\text { Strong recommendation, can apply to } \\
\text { most patients in most circumstances } \\
\text { without reservation. }\end{array}$ \\
\hline $\begin{array}{l}\text { 1B. } \\
\text { Strong } \\
\text { recommendation. } \\
\text { Moderate quality } \\
\text { evidence. }\end{array}$ & $\begin{array}{l}\text { Benefits clearly outweigh risks and } \\
\text { burdens, or vice versa. }\end{array}$ & $\begin{array}{l}\text { Evidence from randomized, controlled trials with important } \\
\text { limitations (inconsistent results, methodologic flaws, indirect } \\
\text { or imprecise), or very strong evidence of some other form. } \\
\text { Further research (if performed) is likely to have an impact on } \\
\text { our confidence in the estimate of benefit and risk and may } \\
\text { change the estimate. }\end{array}$ & $\begin{array}{l}\text { Strong recommendation, likely to apply } \\
\text { to most patients. }\end{array}$ \\
\hline $\begin{array}{l}\text { 1C. } \\
\text { Strong } \\
\text { recommendation. } \\
\text { Low quality } \\
\text { evidence. }\end{array}$ & $\begin{array}{l}\text { Benefits appear to outweigh risks and } \\
\text { burdens, or vice versa. }\end{array}$ & $\begin{array}{l}\text { Evidence from observational studies, unsystematic clinical } \\
\text { experience, or from randomized, controlled trials with serious } \\
\text { flaws. Any estimate of effect is uncertain. }\end{array}$ & $\begin{array}{l}\text { Relatively strong recommendation; } \\
\text { might change when higher quality } \\
\text { evidence becomes available. }\end{array}$ \\
\hline $\begin{array}{l}\text { 2A. } \\
\text { Weak } \\
\text { recommendation. } \\
\text { High quality } \\
\text { evidence. }\end{array}$ & $\begin{array}{l}\text { Benefits closely balanced with risks and } \\
\text { burdens. }\end{array}$ & $\begin{array}{l}\text { Consistent evidence from well-performed randomized, } \\
\text { controlled trials or overwhelming evidence of some other } \\
\text { form. Further research is unlikely to change our confidence in } \\
\text { the estimate of benefit and risk. }\end{array}$ & $\begin{array}{l}\text { Weak recommendation, best action may } \\
\text { differ depending on circumstances or } \\
\text { patient or societal values. }\end{array}$ \\
\hline $\begin{array}{l}\text { 2B. } \\
\text { Weak } \\
\text { recommendation. } \\
\text { Moderate quality } \\
\text { evidence. }\end{array}$ & $\begin{array}{l}\text { Benefits closely balanced with risks and } \\
\text { burdens, some uncertainty in the } \\
\text { estimates of benefits, risks and burdens. }\end{array}$ & $\begin{array}{l}\text { Evidence from randomized, controlled trials with important } \\
\text { limitations (inconsistent results, methodological flaws, } \\
\text { indirect or imprecise), or very strong evidence of some other } \\
\text { form. Further research (if performed) is likely to have an } \\
\text { impact on our confidence in the estimate of benefit and risk } \\
\text { and may change the estimate. }\end{array}$ & $\begin{array}{l}\text { Weak recommendation, alternative } \\
\text { approaches likely to be better for some } \\
\text { patients under some circumstances. }\end{array}$ \\
\hline $\begin{array}{l}\mathbf{2 C} \text {. } \\
\text { Weak } \\
\text { recommendation. } \\
\text { Low quality } \\
\text { evidence. }\end{array}$ & $\begin{array}{l}\text { Uncertainty in the estimates of benefits, } \\
\text { risks, and burdens; benefits may be closely } \\
\text { balanced with risks and burdens. }\end{array}$ & $\begin{array}{l}\text { Evidence from observational studies, unsystematic clinical } \\
\text { experience, or from randomized, controlled trials with serious } \\
\text { flaws. Any estimate of effect is uncertain. }\end{array}$ & $\begin{array}{l}\text { Very weak recommendation; other } \\
\text { alternatives may be equally reasonable. }\end{array}$ \\
\hline
\end{tabular}

Table 2

Summary of definitions.

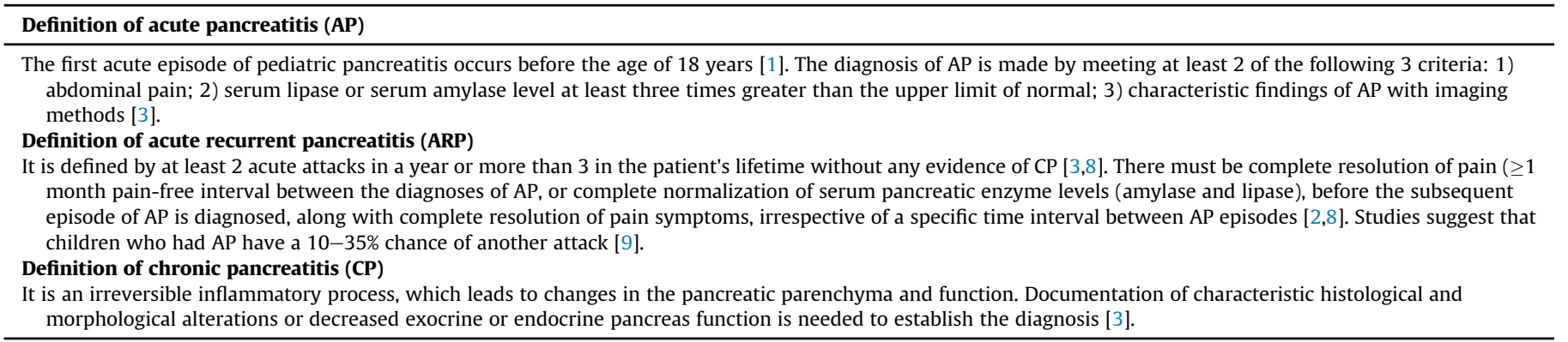

diagnosis is reached are the following: biliary and pancreatic abnormalities, medication-associated, presence of underlying systemic disease, trauma, genetic predisposition, infection, metabolic disorders and autoimmune pancreatitis. (GRADE 1/C, full agreement)

AP-II.1. Pancreaticobiliary anomalies should be ruled out in cases of ARP. (GRADE 2/C, full agreement)

AP-II.2. Cystic fibrosis should be evaluated functionally by performing a sweat chloride measurement (pilocarpine iontophoresis). (GRADE 2C, full agreement)

AP-II.3. In patients with a second episode of idiopathic AP or a first episode of idiopathic AP and a family history of AP or CP, full sequence analysis of the PRSS1, CPA1, SPINK1, CTRC and CFTR gene exons and exon-intron boundaries and testing for the $C E L$ gene pathogenic hybrid allele is recommended in order to explore the etiological background. (GRADE 1/A, full agreement)

AP-III. Prognostic factors: Currently, there is no pediatricspecific clinical prognostic system which can be recommended.
(GRADE 2/C, full agreement)

\section{AP-IV. Imaging}

AP-IV.1. Transabdominal ultrasonography is recommended as a first-choice imaging technique in pediatric AP. (GRADE $1 / B$, full agreement)

AP-IV.2. Contrast-enhanced abdominal computed tomography (CT) is recommended in clinical deterioration in children as per adult guidelines. (Adult evidence level: GRADE 1/C, full agreement)

AP-IV.3. If the clinical presentation of the child suggests pancreatic necrosis contrast-enhanced abdominal CT or MRI is recommended, as per adult guidelines. The optimal timing of the scan is at least $72-96 \mathrm{~h}$ after presentation with pancreatitis. (Adult evidence level: GRADE 1/B, full agreement)

AP-IV.4. ERCP is not recommended for diagnostic purposes. (GRADE 1/C, strong agreement) 
AP-IV.5. Endoscopic ultrasonography (EUS) can be used in children in cases of suspected autoimmune or biliary pancreatitis or for treatment of local complications, such as pseudocysts or walledoff necrosis (WON). (GRADE 2/C, full agreement)

AP-IV.6. MRCP is recommended for suspected pancreatic ductal leak or injury or suspected biliary tract abnormalities. (GRADE 2/C, full agreement)

\section{AP-V. Therapy}

\section{$A P-V .1$. Fluid replacement therapy}

AP-V.1.1. Administration of dextrose containing crystalloids is recommended as the initial choice for replacement fluid therapy in AP. (GRADE 2/B, full agreement)

AP-V.1.2. Due to lack of unequivocal guidelines, early aggressive fluid management (at a rate of more than 1.5-2 times the maintenance rate of IV fluids) is recommended in children in the first $24 \mathrm{~h}$. (GRADE 2/C, full agreement)

AP-V.2. Analgesia: Analgesia should be provided when indicated. No specific pain management guidelines are available in pediatric AP. (GRADE 2/C, full agreement)

\section{AP-V.3. Nutrition}

AP-V.3.1. Oral feeding can be started as soon as tolerated even in the presence of systemic inflammation and before the amylase or lipase values have decreased. (Adult evidence level: GRADE 2/B, full agreement)

AP-V.3.2. If adequate oral feeding is not tolerated or the required calories cannot be achieved by oral feeding within $72 \mathrm{~h}$, enteral tube feeding is recommended. (Adult evidence level: GRADE 1/A, full agreement)

AP-V.3.3. In AP, enteral nutrition can be achieved either via nasogastric or nasojejunal tube feedings. There are no comparative studies between gastric and jejunal feeding in pediatric AP. (Adult evidence level: GRADE 1/A, full agreement)

AP-V.3.4. Elemental and polymeric formulas are both appropriate in the management of AP. (Adult evidence level: GRADE 2/B, full agreement)

AP-V.3.5. Complete parenteral feeding is used as a second-line treatment in AP when enteral nutrition is not tolerable for the patient and additional nutrition is necessary. (Adult evidence level: GRADE 1/A, full agreement)

\section{AP-V.4. Antibiotic therapy}

AP-V.4.1. Regardless of the severity of the pancreatitis or existing necrosis, routine use of prophylactic antibiotics is not recommended in AP. (Adult evidence level: GRADE 1/B, strong agreement)

AP-V.4.2. In cases of systemic infectious complications, cholangitis or suspected infected pancreatic necrosis, antibiotic treatment is recommended. (GRADE $1 / B$, full agreement); AP-VI. Management of biliary pancreatitis

AP-VI.1. ERCP is not indicated in predicted mild biliary pancreatitis without cholangitis. (Adult evidence level: GRADE 1/A, full agreement)

ERCP is probably not indicated in predicted severe biliary pancreatitis without cholangitis. (Adult evidence level: GRADE 1/B, full agreement)

ERCP is probably indicated in biliary pancreatitis with common biliary obstruction.

(Adult evidence level: GRADE $1 / C$, full agreement)

ERCP is indicated patients with biliary pancreatitis and cholangitis. (Adult evidence level: GRADE 1/B, full agreement)

AP-VI.2. In cases of severe cholangitis ERCP should be done urgently within $24 \mathrm{~h}$. In other cases of cholangitis and/or obstruction. ERCP should be performed within $72 \mathrm{~h}$. (Adult evidence level:
GRADE $1 / B$, full agreement)

AP-VI.3. For uncomplicated biliary pancreatitis, cholecystectomy is recommended during the index admission if possible or, if not possible, within 30 days of the first admission for mild cholelythiasis-associated AP in children. Importantly, if cholecystectomy is not performed, the patient remains at risk of another episode of AP and complications of gallstones. (Adult evidence level: GRADE 1/B, full agreement; Pediatric evidence level: GRADE $1 / C$, full agreement)

\section{AP-VII. Complications}

AP-VII.1. Common indications for intervention in necrotizing pancreatitis include:

1) Confirmed cases of infected necrotizing pancreatitis or if strong suspicion of the same with decline in clinical status, especially with WON.

2) Unconfirmed cases of infected necrotizing pancreatitis with multiple organ failure, especially with WON.

3) Abdominal compartment syndrome

4) Ongoing acute bleeding

5) Bowel ischemia

6) WON causing gastric outlet, bowel or biliary obstruction

(Adult evidence level: GRADE 1/C, full agreement)

AP-VII.2. Routine percutaneous fine-needle aspiration (FNA) of peripancreatic necrotic collections is unnecessary for confirming bacterial infection, as clinical (continuous fever, elevated inflammatory markers) and imaging signs (gas in the collections) are valid predictors of infection necrosis in majority of the cases. FNA could help with the confirmation of infection, but there is high prevalence of false negatives (12-25\%). (Adult evidence level: GRADE $1 / C$, full agreement)

AP-VII.3. Regarding the optimal timing of intervention in suspected and confirmed cases of infected pancreatic necrosis, only adult recommendations are available, relevant clinical pediatric studies have not been conducted. In confirmed or suspected infected necrotizing pancreatitis, invasive intervention (percutaneous catheter drainage, endoscopic transluminal drainage or necrosectomy) should be delayed as much as possible, but at least by 4 weeks after the initial presentation so that the collection can transform into WON. The timing of intervention should be balanced between the need to intervene and the benefits of delaying the intervention. (Adult evidence level: GRADE 1/C, full agreement)

AP-VII.4. The optimal intervention strategy in cases of suspected or confirmed infected necrotizing pancreatitis is initially imagingguided percutaneous (retroperitoneal) catheter drainage or endoscopic transluminal drainage, which, if necessary, can be followed by endoscopic or surgical necrosectomy. (Adult evidence level: GRADE 1/B, full agreement)

AP-VII.5. In the cases of an asymptomatic pancreatic pseudocysts, regardless of size, location, and/or extension observation is appropriate. When pancreatic pseudocysts are symptomatic, endoscopic intervention should be the therapy of first choice in experienced centers. (Adult evidence level: GRADE 1/C, full agreement)

\section{Acute recurrent pancreatitis (ARP) in children}

ARP. Definition: It is defined by at least 2 acute attacks in the patient's lifetime without any evidence of CP. There must be complete resolution of pain ( $\geq 1$ month pain-free interval between the diagnoses of AP, or complete normalization of serum pancreatic enzyme levels (amylase and lipase), before the subsequent episode 
of AP is diagnosed, along with complete resolution of pain symptoms, irrespective of a specific time interval between AP episodes. (GRADE 2/B, full agreement).

\section{Chronic pancreatitis (CP) IN children}

CP-I. Diagnosis and definition: $\mathrm{CP}$ is a progressive inflammatory process that leads to the destruction of pancreatic parenchyma and has a negative impact on pancreatic function. The diagnosis of $\mathrm{CP}$ requires characteristic histological and morphological findings with decreased pancreatic function (endocrine or exocrine). (GRADE 1/B, strong agreement).

\section{CP-II. Etiological factors in childhood onset CP}

CP-II.1. Genetic variations are the most common risk factors for development of pediatric CP. (GRADE 1/A, full agreement) However, other risk factors such as obstruction, autoimmune and toxic and metabolic factors also need to be examined. (GRADE 2/B, full agreement)

CP-II.2. There is an association between CP and cystic fibrosis (CF), therefore a sweat test should be performed to screen for $\mathrm{CF}$ as a possible etiological factor in children. (GRADE 1/A, strong agreement)

\section{CP-III. Treatment of acute on CP in children}

CP-III.1. The treatment for acute episodes of pancreatitis in pediatric patients with $\mathrm{CP}$ does not differ from the management of the initial episode. Nutrition for children during an episode of acute on $\mathrm{CP}$ can be administered in the same way as in adult patients. (GRADE 1/C, full agreement)

CP-III.2. The general use of antibiotics in children is not recommended in an acute exacerbation of CP. (Adult evidence level: GRADE 1/C, strong agreement)

\section{$C P$-IV. Imaging in $C P$ in children}

CP-IV.1. Transabdominal ultrasound, EUS, CT and MRI can be used during the management of $C P$ in childhood. (GRADE 1/B, strong agreement)

CP-IV.2. Yes, EUS can be performed. This imaging examination is a valid option in children for the assessment of biliary stones. In addition, EUS is helpful during the treatment of the complications. (GRADE 1/B, full agreement)

CP-IV.3. MRCP should be the first choice for the cross-sectional imaging of the pancreatic and biliary ducts. (GRADE $1 / B$, full agreement)

CP-IV.4. The sensitivity of MRCP can be improved by the administration of secretin. (GRADE 1/B, full agreement)

$C P-V$. Endoscopic, interventional and surgical treatment of $C P$ in children

CP-V.1. ERCP can be safely performed in children and should be reserved for interventions in experienced centres. In the presence of obstruction with concomitant signs or the presence of stones in the pancreatic duct, therapeutic intervention (sphincterotomy, stent insertion, dilatation of duct strictures, or stone extraction) by ERCP can be chosen. Randomized studies on this subject are lacking in the pediatric population. (GRADE 1/C, full agreement

CP-V.2. After failing conservative or endoscopic therapy, surgical intervention may be indicated in children with $\mathrm{CP}$, especially if chronic pain persists and the child has frequent recurrent attacks leading to numerous hospital stays. Preservation of pancreatic function should be the primary goal during surgical procedures. (GRADE 1/C, full agreement)

\section{$C P$-VI. Pain management in $C P$ in children}

CP-VI.1. The experience with pain management in pediatric $\mathrm{CP}$ is limited. Endoscopic and/or surgical interventions may be needed to control pain in pediatric CP. In general, non-narcotic analgesics should be the first line of therapy for pain and narcotics reserved for uncontrollable pain. (GRADE 1/C, full agreement)

\section{CP-VII. Enzyme replacement therapy (PERT) in CP in children}

CP-VII.1. For PERT in pediatric CP, guidelines for cystic fibrosis induced exocrine pancreatic insufficiency (EPI) should be used. Children less than 4 years of age should receive 1000 lipase units $/ \mathrm{kg}$ per meal; 1000-2500 lipase units/kg per meal for those $>4$ years of age; and 40,000-50,000 units lipase/meal for children of adult size. For snacks, half of the above dosing is recommended. (GRADE $1 / C$, full agreement)

CP-VII.2. PERT in children and adolescents with CP should be considered when growth and/or weight gain are unsatisfactory or ongoing symptoms of EPI are present. (GRADE $1 / C$, strong agreement)

CP-VII.3. Administration of acid suppressive drugs (either a proton pump inhibitors (PPI) or $\mathrm{H} 2$ blockers) is recommended when severe malabsorption occurs in spite of appropriate PERT in children with CP. (GRADE 1/C, strong agreement)

\section{Evidence review that served as the basis for the recommendations}

\section{Acute pancreatitis}

AP-I. Diagnosis and definition of acute pediatric pancreatitis AP-I.1. What are the requirements for the diagnosis of AP?. A diagnosis of AP is achieved by meeting at least 2 of the following 3 criteria:1) abdominal pain; 2) serum lipase or serum amylase level at least three times greater than the upper limit of normal; 3 ) characteristic findings of AP with imaging methods [3]. (GRADE 1/B, full agreement)

There were many attempts to put together the best diagnostic criteria for AP in children. The best result was achieved when the clinical symptoms, laboratory and imaging characteristics of $\mathrm{AP}$ were considered together. Although lipase seems to be better biomarker than amylase and CT has better diagnostic yield than US, all of the modalities can be used during the diagnostic workup [8].

AP-I.2. What are the characteristics of abdominal pain which suggest $A P$ in children?. Diffuse, epigastric, persistent or minimally easing abdominal pain suggests AP in childhood. (GRADE $1 / C$, full agreement)

Abdominal pain is the leading symptom in $68-95 \%$ of the cases $[9,10]$ and in $62-89 \%$ of the cases it is localized to the epigastrium [11-13]. Pain radiating to the back is present in only $1.6-5.6 \%$ of the cases in children [13-15]. $12-20 \%$ of the pediatric patients with AP have diffuse abdominal pain [1,16]. Abdominal pain is present in only $29 \%$ of patients younger than 3 years old $[10,17]$.

AP-I.3. What other clinical symptoms could suggest AP?. In children, especially in infants and in toddlers, vomiting, irritability and abdominal distension may suggest AP. (GRADE 1/B, full agreement)

The second most common symptom is vomiting, which occurs in $45-85 \%$ of the patients. Less common symptoms are irritability, abdominal discomfort, abdominal distension, tachycardia, 
hypotension and jaundice. These symptoms usually present in children younger than 3 years old $[10,17]$.

AP-I.4. What laboratory tests should be obtained to screen for pancreatitis in a child with abdominal pain?. Measurement of serum amylase and/or lipase among the routine laboratory tests is recommended in the presence of abdominal pain. (GRADE $1 / C$, full agreement)

Studies show that the number of diagnosed with AP strongly correlates with the frequency of tested serum amylase and lipase levels [1]. According to international studies, serum amylase was elevated in $50-85 \%$ of the cases and serum lipase was elevated in $77-100 \%$ of the cases. Elevated lipase levels were found in $100 \%$ of the infants and toddlers with AP, however only $40-60 \%$ of them had elevated amylase levels, based on two research centers' investigations. An Australian study clearly showed that elevation in serum lipase contributed to the diagnosis more often than amylase [8]. This is most likely a result of differences in digestive enzyme expression during the first several months of life [12,17]. This age group needs a special approach for establishing the diagnosis. In a significant portion of children one or both enzyme levels were elevated. Both parameters should be tested for optimal results [17].

\section{AP-II. Etiology of acute pediatric pancreatitis in children}

AP-II.1. What etiological factors should be considered in case of pediatric AP? Etiological factors that should be considered after the diagnosis is reached are the following: biliary and pancreatic abnormalities, medication-associated, presence of underlying systemic disease, trauma, genetic predisposition, infection, metabolic disorders and autoimmune pancreatitis. (GRADE 1/C, full agreement)

AP-II.1.1. Biliary abnormalities: Pancreaticobiliary anomalies should be ruled out in cases of ARP. (GRADE 2/C, full agreement)

This etiology includes pancreatitis due to gallstone impaction in the distal common bile duct, microlithiasis with very small stones or sludge, and pancreaticobiliary anomalies [18,19]. Biliary abnormalities as an etiology for pediatric pancreatitis are more common than previously thought and, as in adults, most pediatric case series report this as the most common reason for AP in children [10]. However, the frequency ranges widely in the literature, from 3 to $30 \%$. Although each age group is affected, older children and teenagers are at greatest risk [12]. In $10 \%$ of cases, gallstones are the underlying cause in newborns and infants. Gallstones or other biliary disorders should be investigated particularly if the patient has jaundice and/or elevated transaminase levels and/or hyperbilirubinemia [12,17,20-22]. Pancreatobiliary anatomical anomalies increase the risk of pancreatitis. These include pancreas divisum, pancreaticobiliary maljunction (also known as a long common channel), annular pancreas, and choledochal cysts. Pancreas divisum occurs in about $7 \%$ of the general population [23]. Most patients with pancreas divisum never develop pancreatitis, although there appears to be a higher number of pancreas divisum cases among patients with pancreatitis compared to nonpancreatitis control groups [12,20,24].

AP-II.1.2. Medications: The most common medications associated with AP in children are valproic acid, mesalazine, thiopurines, and asparaginase [12,25].

AP-II.1.3. $13-34 \%$ of the cases are idiopathic $[12,17,20,26]$, although discovery of new genes genetic risk factors has been narrowing the incidence of idiopathic pancreatitis [27].

AP-II.1.4. Systemic diseases: Based on observational epidemical studies, AP in the setting of systemic diseases ranges from 3.5 to $48 \%[17,28]$. It has been associated with sepsis, shock (with or without sepsis), hemolytic uremic syndrome, systemic lupus erythematosus and inflammatory bowel disease (IBD). Among these diseases, hemolytic uremic syndrome had the highest prevalence rate. $2.7 \%$ of IBD patients will develop pancreatitis [10,20]. Conversely, $30 \%$ of patients with type 2 autoimmune pancreatitis (also known as idiopathic duct centric pancreatitis, IDCP) have or will develop IBD [29,30]. Celiac disease should also be ruled out in accordance with the current diagnostic criteria. In a Swedish study, patients with celiac disease had three times risk of developing pancreatitis [31]. If a patient with celiac disease has abdominal pain despite negative serology and a strictly followed diet, pancreatitis should be considered. In another study, $7 \%$ of the adult patients with AP and suspected stenosis of the papilla of Vater had celiac disease [32].

AP-II.1.5. Traumatic injuries: Although the incidence of pancreatitis caused by trauma is not as high as previously thought, it is still an important etiological factor for pediatric pancreatitis. The most common cause is accidental blunt trauma, but child abuse is also a notable factor. According to studies, in $10-40 \%$ of the cases of AP, trauma was an etiological factor (motorcycle accident, sport injury, accidental fall and child abuse) $[17,18,20]$.

AP-II.1.6. Infections have been reported in less than $10 \%$ of the cases. In some cases infections also caused fever and upper airway symptoms, and in most cases mumps virus was detected. Other viruses associated with pancreatitis include hepatitis A, rotavirus, hepatitis E, varicella zoster virus and adenovirus. Epstein-Barr virus, cytomegalovirus, herpes simplex and Coxsackie B viruses can also cause pancreatitis [12,17,18,20,32]. Diseases of viral or other infectious origin (bacterial, parasite) should also be ruled out based on the clinical picture (fever, diarrhea, airway or dermatological symptoms) and other laboratory tests.

AP-II.1.7. Metabolic disorders are present in $2-7 \%$ of the cases. The most common metabolic disorders are diabetic ketoacidosis, hypertriglyceridemia and hypercalcemia [6,12,17,20,32,33]. It is recommended to test serum triglycerides and serum calcium levels in every child with AP.

AP-II.1.8. Genetic susceptibility: Pediatric AP and RAP often develop in the background of genetic susceptibility and genetic testing is warranted two or more episodes or even after an isolated episode if there is a family history of AP or CP. Testing for pathogenic variants in the PRSS1 [34], SPINK1 [35], CTRC [36], CPA1 [37] and CFTR [38,39] genes and for the pathogenic CEL [40] hybrid allele are recommended. Variants in the PRSS1 and CPA1 genes may be associated with a family history of pancreatitis or even autosomal dominant hereditary pancreatitis. Children with a single episode of AP are at risk for developing a second episode. However, genetic testing is [41] cumbersome and expensive. There is usually no therapeutic consequence, but it may assist in long term prognosis.

AP-II.1.9. Autoimmune pancreatitis:. Autoimmune CP type 1 (classic form of AIP) related to elevated IgG4 plasma levels is not common diagnosed in children whereas Type 2 (often called idiopathic duct-centric $\mathrm{CP}$ ) identical with the type seen in adults is more likely to be found. Both diseases respond well to corticosteroid therapy and have low likelihood of recurrence [4].

AP-II.2. How should CF be ruled out in cases of AP in children?. Cystic fibrosis should be evaluated functionally by performing a sweat chloride measurement (pilocarpine iontophoresis). (GRADE 2/C, full agreement)

AP-II.3. What kind of genetic testing is recommended in cases of pediatric $A P$ and $C P$ ?. In patients with a second episode of idiopathic $\mathrm{AP}$ or first episode of idiopathic AP and a family history of $\mathrm{AP}$ or $\mathrm{CP}$, full sequence analysis of PRSS1 [34], CPA1 [37], SPINK1 [35], CTRC [36] and CFTR [38] gene exons and exon-intron boundaries and testing for the CEL [40] gene pathogenic hybrid allele is recommended in order to explore the etiological background. (GRADE 1/A, 


\section{full agreement)}

The presence of mutations in the above mentioned genes increases the risk of ARP and CP. Hereditary pancreatitis associated with mutations in PRSS1, especially p.R122H, that could considerably increase the risk of pancreatic adenocarcinoma [34]. Knowing the genetic risk factors may not alter the therapy, but it helps to understand the disease's etiological background for the disease and may lead to future targeted investigation.

\section{AP-III. Prognostic factors in pediatric AP}

AP-III.1. Which is the best clinical system to predict the severity of the pediatric AP? Currently, there is no pediatric-specific clinical prognostic system which can be recommended. (GRADE 2/C, full agreement)

In adult reports, systemic inflammatory response syndrome (SIRS) is used for predicting the severity of AP, as persistent SIRS may lead to organ failure. The revised Atlanta Criteria define severe $\mathrm{AP}$ as AP with persistent organ failure for more than $48 \mathrm{~h}$ [42]. There are many adult pancreatitis severity scoring systems. These include the Ranson [43], Glasgow [44], Modified Glasgow [45], Bedside Index of Severity in AP (BISAP) [46], APACHE II [47,48], as well as single serum biomarkers (i.e. the blood urea nitrogen, BUN) [49] to assess the severity of the disease. The Balthazar score system, which is based on CT findings, has $81 \%$ sensitivity, $76 \%$ specificity, $62 \%$ positive predictive value, and a $90 \%$ negative predictive value [50].

Several studies in children have also attempted to determine the best scoring system to predict the development of severe AP. DeBanto et al. reported the first scoring. It was termed as the Pediatric AP Score (PAPS) [28], and it was based on demographic, clinical and laboratory values. It utilizes 4 parameters at admission (age: $<7$, weight: $<23 \mathrm{~kg}$, white blood cell count: $>18.5 \mathrm{G} / \mathrm{l}, \mathrm{LDH}$ : $>2000 \mathrm{U} / \mathrm{l})$ and 4 more during the initial $48 \mathrm{~h}$ after admission $\left(\mathrm{Ca}^{2+}\right.$ : $<8.3 \mathrm{mg} / \mathrm{dl}$, albumin: $<2.6 \mathrm{~g} / \mathrm{dl}$, fluid sequestration: $>75 \mathrm{ml} / \mathrm{kg} /$ $48 \mathrm{~h}$, and 48 -h rise in BUN: $>5 \mathrm{mg} / \mathrm{dl}$ ) to evaluate the severity of AP. PAPS had a $70 \%$ sensitivity, $79 \%$ specificity, $91 \%$ negative predictive, and $45 \%$ positive predictive values. In two large case series, however, the sensitivity for predicting severe AP using the PAPS, however, was low. Nonetheless, a high white blood cell count (>18.5 G/ 1), low serum calcium level ( $<8.3 \mathrm{mg} / \mathrm{dl})$, high BUN level $(>5 \mathrm{mg} / \mathrm{dl})$ assessed at admission were good, independent predictive factors [28,51].

In a retrospective study of children from Australia, serum lipase values greater than or equal to 7 times the upper limit of normal in the initial $24 \mathrm{~h}$ (or Day 1) after presentation to the hospital predicted the development of severe AP. The sensitivity (85\%) and negative predictive values (89\%) were high, but the specificity (56\%) and positive predictive value (46\%) were low [20]. The scoring system had lower sensitivity and specificity in more recent validation reports [52,53]. The same original group went on to combine this parameter along with measurements on Day 2 after presentation of a greater than $50 \%$ reduction in the lipase from Day 1 and a trough calcium less than $2.15 \mathrm{mmol} / \mathrm{L}$ [52]. This combination improved the specificity to $89 \%$, although the sensitivity was only $46 \%$.

Szabo et al. examined pediatric severe AP cases from three hospitals in the United States and identified changes in lipase, albumin, and white blood cell count obtained within $24 \mathrm{~h}$ of admission to the hospital as predictors of severity [54]. Overall, the studies suggest that unlike in a seminal [55], in children serum lipase may provide some value in predicting pancreatitis severity $[56,57]$.

Suzuki et al. evaluated what they termed as the modified Ministry of Health, Labor and Welfare of Japan (JPN) scoring system in a group of children with severe AP from Tokyo [58]. The original JPN scoring system consisted of several serum values and the partial pressure of arterial oxygen, while the modified scoring had pediatric SIRS, age, and weight added to it. Authors reported that the JPN score had a sensitivity of $80 \%$ and specificity of $96 \%$.

There are several reasons why predicting severe AP in children has been difficult. Published prognostic scoring systems in children lack a standardized definition of the condition. Some include the presence of pancreatic collections such as pseudocysts in the definition, while others use the need for intensive care unit (ICU) admission to define severe AP. It is almost needless to say that these selections are subjectively determined at most institution. Another issue is that few children comply with the strict definition of severe AP imposed by the revised Atlanta Criteria of persistent organ failure [10]. Some of the scoring systems, are also complicated and impractical similarly to the adult ones. Future efforts should thus be aimed at standardizing definitions, pooling patient cases in a multicenter collaborations and balancing the ease of use with test performance.

\section{AP-IV. Imaging in pediatric AP}

AP-IV.1. What is the first-line imaging in suspected pediatric pancreatitis?. Transabdominal ultrasonography is recommended as a first-choice imaging technique in pediatric AP. (GRADE $1 / B$, full agreement)

In children, no controlled trials have been conducted on the use of imaging tools in suspected AP. Recommendations concerning imaging methods are based on adult clinical experiences. Transabdominal ultrasound is easy to perform, widely available, noninvasive with no radiation exposure and no requirement for anesthesia in children, thus it is an optimal choice as a first-line imaging technique in AP. The diagnostic features of AP including, the parenchymal changes, edema and peripancreatic fluid collections can all be readily recognized on transabdominal ultrasound. Furthermore, it is a better imaging modality to assess for identify choledocholithiasis or presence of stones in the common bile duct. Transabdominal ultrasound has been performed in the majority of children (56-84\%) in suspected cases of AP [20,59]. According to publications sonographic changes indicative of AP are found in about one third to one half of pediatric patients [32,59].

AP-IV.2. What are the indications for early abdominal CT? Contrast-enhanced abdominal $\mathrm{CT}$ is recommended in clinical deterioration in children as per adult guidelines. (Adult evidence level: GRADE 1/C, full agreement)

In younger children, however, due to the radiation and the necessity of anesthesia/sedation, abdominal CT is not recommended as a first line investigation. In adults, contrast CT scan is the most adequate modality for assessing parenchymal changes and the complications of AP. The indications for contrast abdominal CT in older children - similarly to adults - are the following: 1) diagnostic uncertainty, 2) unsuccessful conservative therapy, deteriorating clinical status, 3 ) estimation of the extent and necrosis in severe AP, and 4) for assessment of complications [60-62].

Abdominal CT is the second most commonly used imaging modality, yet in most pediatric cases CT imaging is not necessary for the diagnosis. In studies, abdominal CT was performed in a third of suspected pediatric AP cases, however the sensitivity of the test was low for parenchymal changes or for peripancreatic fluid collections (60-75\%) [12,32].

AP-IV.3. Which imaging modalities are recommended in suspected pancreatic necrosis and when?. If the clinical presentation of the child suggests necrosis, contrast-enhanced abdominal CT or MRI is recommended, as per adult guidelines. The optimal timing of the scan is at least $72-96 \mathrm{~h}$ after presentation with pancreatitis. (Adult 
evidence level: GRADE 1/B, full agreement)

Regarding abdominal CT scan in practice, general pediatric radiology guidelines are to be applied. CT scan can provide help in complicated, severe cases, as these show necrosis and bleeding more clearly than MRI [61].

AP-IV.4. When to perform ERCP in AP in children?. ERCP is not recommended for diagnostic purposes. (GRADE $1 / C$, strong agreement)

MRCP and EUS have lessened the importance of ERCP in the diagnosis of pancreatobiliary diseases. ERCP could play a role along with MRCP in the assessment and treatment of pancreatic duct injuries in cases of pancreatic trauma $[63,64]$ and can be performed on children with appropriately sized tools, even with great care on young infants. The effectiveness of the examination in children exceeds $90 \%$, while the complication rate is $4-9.5 \%[65,66]$. In children, the method requires anesthesia/sedation.

AP-IV.5. What are the main indications for endoscopic ultrasound (EUS) in pediatric AP?. EUS is an useful method of examination in children in cases of suspected autoimmune, biliary pancreatitis or for treatment of local complications, such as pseudocysts or WON (GRADE 2/C, full agreement)

Considering the size of the endoscope and the technical conditions, the examination can be performed from about 5 years of age with special indications, including the assessment of biliary stones and the treatment of complications [59,64,67].

AP-IV.6. When should MRCP be performed in pediatric AP?. MRCP is recommended for suspected pancreatic ductal leak or injury or suspected biliary tract abnormalities. (GRADE $2 / C$, full agreement)

The examination requires anesthesia or sedation if performed on younger children, especially below the age of 6 . MRCP is an appropriate method of diagnostic modality of the biliary system in children and should be the first choice of imaging for pancreaticobiliary system in children $[64,68]$.

\section{$A P-V$. Treatment of pediatric $A P$}

$A P-V .1$. Fluid therapy. No controlled pediatric trials are available on the type and volume of parenteral fluids used in fluid resuscitation, therefore we consider adult data [28].

AP-V.1.1. Which intravenous fluids should be used in AP? Administration of dextrose containing crystalloids is recommended as the initial choice for replacement fluid therapy in AP. (GRADE 2/B, full agreement)

Few studies have been conducted on the effects of parenteral fluids on the outcome of AP [69-71]. A multicenter study of 40 cases of adult AP showed a significant decrease in SIRS incidence with Ringer's solution compared to physiological saline [69]. In adults the administration of plasma expanders is not recommended based on current evidence $[60,69]$. Aggressive intravenous hydration with lactated Ringer's solution appears to reduce the development of post-ERCP pancreatitis and is not associated with volume overload [72]. Other studies show no added benefit from lactated Ringer's solution compared to normal saline in terms of mortality and the duration of hospital stay [73].

AP-V.1.2. What should be the volume and speed of fluid replacement?. Due to lack of unequivocal guidelines, early aggressive fluid management (a rate or more than 1.5-2 times the maintenance rate of IV fluids) is recommended in children in the first $24 \mathrm{~h}$. (GRADE 2/C, full agreement)

Early fluid replacement helps with the correction of hypovolemia, increases the perfusion of the pancreas, improves the microcirculation and reduces necrosis. Neither adults nor children have an established guideline related to the rate or volume of fluid infusion. Data shows that fluid resuscitation within the window of intervention (first 24-72 h) reduces morbidity and mortality in adults [60-62]. Additional fluid correction should be tailored to the child's hemodynamic status. The effects of fluid resuscitation can be measured by monitoring one or more of the following parameters: 1) Non-invasive methods such as pulse rate, blood pressure, capillary refill time, diuresis $(0.5-1.0 \mathrm{ml} / \mathrm{kg} / \mathrm{h}) ; 2)$ invasive methods, which should be employed in the intensive care unit (ICU).

In children, aggressive fluid hydration has been defined as a rate of more than 1.5-2 times the maintenance rate of IV fluids, and that was associated with improved outcomes with fewer ICU admissions due to SIRS, and shortened hospital stays [74]. From multiple adult studies it can be concluded that aggressive resuscitation is associated with improved outcomes in AP, but overresuscitation should be avoided. A regimen of IV fluids within $4 \mathrm{~h}$ of diagnosis to aggressive $(20 \mathrm{ml} / \mathrm{kg}$ bolus followed by $3 \mathrm{ml} / \mathrm{kg} / \mathrm{h})$ vs. standard ( $10 \mathrm{ml} / \mathrm{kg}$ bolus followed by $1.5 \mathrm{mg} / \mathrm{kg} / \mathrm{h}$ ) hydration with lactated Ringer's solution was associated with greater rate of clinical improvement [75].

AP-V.2. Pain management. Analgesia should be provided when indicated. No specific pain management guidelines are available in pediatric AP. The World Health Organization recommendations for pain management in children should be considered [72]. In the presence of mild pain, paracetamol and ibuprofen are the medicines of choice. If pain severity associated with a medical illness is assessed as moderate or severe, the administration of a strong opioid is necessary. Medication should be administered on a regular schedule for persisting pain. Analgesics should be administered to children by the simplest, most effective, and least painful route, making oral formulations the most convenient and the least expensive route of administration. The choice of alternative routes of administration (intravenous, subcutaneous, rectal or transdermal) when the oral route is not available should be based on clinical judgement, availability and patient preference. The intramuscular route of administration is painful and is to be avoided [76].

Thus far, randomized controlled trials (RTCs) comparing different analgesics have been of low quality and have not found in clear favor for any particular analgesic to be used for pain relief in AP.

Opioid drugs, such as meperidine increase the tone of the sphincter of Oddi, but clinical studies have failed to confirm declining outcomes associated with their use. Meperidine is a more common choice, as it has fewer side effects, while the half-life if morphine is longer.

AP-V.3. Nutrition. The nutrition of children with AP is carried out according to recommendations based on clinical experience in adults and the limited studies in pediatrics. No RCTs have been done in children to address the role of nutrition in AP [18, 22, 23, 29, 30].

AP-V.3.1. When should oral feeding start?. Oral feeding can be started as soon as tolerated even in the presence of systemic inflammation and before the amylase or lipase values have decreased. (Adult evidence level: GRADE 2/B, full agreement)

In mild AP oral feeding can be initiated within $24-48 \mathrm{~h}$ after admission [77]. It is not necessary to wait for all the laboratory parameters to normalize or for all pain to cease. A RCT in adults found that an immediate normal diet was safe and led to shorter hospital stay [78]. In another adult study, they administration of solid food was recommended immediately instead of starting with a liquid diet [79]. A pediatric study that examined the role of nutrition in AP, showed that feeds within $24 \mathrm{~h}$ of admission are 
feasible, safe and not associated with increased pain compared to the group of patients that didn't received feeds [80,81].

AP-V.3.2. Should we choose tube feeding?. If adequate oral feeding is not tolerated or the required energy cannot be achieved by oral feeding within $72 \mathrm{~h}$, enteral tube feeding is recommended. (Adult evidence level: GRADE 1/A, full agreement)

Enteral feeding should be started orally, through nasogastric tube [28] or through nasojejunal tube $24-48 \mathrm{~h}$ after admission, in addition adequate fluid therapy and pain management. Generally, oral feeding can be initiated at this time in the majority of cases of mild AP. In AP, early enteral nutrition has been found to reduce the incidence of complications and improve outcomes regardless of the severity of the disease compared to parenteral nutrition [31]. In severe AP, the initiation of enteral nutrition within $48 \mathrm{~h}$ improved outcomes compared to the initiation after 7 days. In a randomized trial of 50 adult patients enteral feeding led to fewer infections, organ failure, and reduced mortality and hospital stay [42,60,61].

$A P-V .3 .3$. Should we choose nasojejunal or nasogastric tube feeding?. In AP, enteral nutrition can be achieved either via nasogastric or nasojejunal tube feedings. (Adult evidence level: GRADE 1/ A, full agreement)

Several RCTs conducted in adults confirmed that nasogastric feeding is equivalent to the nasojejunal route with regard to complications and clinical course [82-87]. Two RCTs with smaller sample size group showed that nasogastric feeding is applicable and safe [86,87]. However, we have note that some adult patients might not tolerate nasogastric nutrition due to decreased gastric emptying or worsening pain $[60,88]$. There are no comparative studies comparing, gastric with jejunal feeding in pediatric AP.

AP-V.3.4. Which formulas should we use?. Elemental and polymeric formulas are both appropriate in the management of AP. (Adult evidence level: GRADE 2/B, full agreement)

According to a recently published meta-analysis in which 20 RCTs were reviewed, polymeric formulas proved to be equivalent to more expensive semi-elemental formulas with regard to tolerability, infectious complications and mortality [89].

$A P-V .3 .5$. Is there an indication for parenteral nutrition in AP?. Complete parenteral nutrition is used as a second-line treatment in $\mathrm{AP}$, when enteral nutrition is not tolerated for the patient and additional nutrition is necessary. (Adult evidence level: GRADE 1/A, full agreement); The only indication for complete parenteral nutrition is when enteral feeding is impossible due to prolonged ileus, pancreatic fistula or abdominal compartment syndrome [60].

\section{AP-V.4. Antibiotic therapy}

AP-V.4.1. Should prophylactic antibiotics be used in AP? Regardless of the severity of the pancreatitis or existing necrosis, routine use of prophylactic antibiotics is not recommended. (Adult evidence level: GRADE 1/B, strong agreement)

There are no controlled trials addressing antibiotic use in pediatric AP, so following the adult guidelines is recommended [60].

AP-V.4.2. When should antibiotic therapy be used in pediatric AP? In cases of systemic infectious complications, cholangitis or suspected infected pancreatic necrosis, antibiotic treatment is recommended. (GRADE 1/B, full agreement)

Most pediatricians recommend antibiotics if systemic symptoms (recurring fever, increasing abdominal pain and leukocytosis) are present or in cases of biliary pancreatitis with cholangitis [20].

\section{AP-VI. Management of biliary AP in children}

Application of the guidelines for the treatment of biliary AP in adults is recommended due to minimal data from pediatric studies. Since the last pediatric AP guidelines were drafted on the role of ERCP in biliary pancreatitis, adult studies have mainly focused on the efficacy and safety of ERCP with biliary pancreatitis.

\section{AP-VI.1. What are the indications for ERCP and sphincterotomy in} biliary pancreatitis?

ERCP is not indicated in predicted mild biliary pancreatitis without cholangitis. (Adult evidence level: GRADE 1/A, full agreement)

ERCP is probably not indicated in predicted severe biliary pancreatitis without cholangitis. (Adult evidence level: GRADE 1/B, full agreement)

ERCP is probably indicated in biliary pancreatitis with common bile duct obstruction. (Adult evidence level: GRADE $1 / C$, full agreement)

ERCP is indicated in patients with biliary pancreatitis and cholangitis. (Adult evidence level: GRADE 1/B, full agreement)

According to a meta-analysis of 7 RCTs with 757 adult patients published in 2012, early ERCP did not reduce the frequency of complications regardless of severity, although the analysis did support the necessity for the procedure in cholangitis and biliary obstruction $[60,63,64,90]$.

\section{AP-VI.2. What is the optimal timing of ERCP?}

In cases of severe cholangitis ERCP should be done urgently within $24 \mathrm{~h}$. In other cases of cholangitis and/or obstruction. ERCP should be performed within $72 \mathrm{~h}$. (Adult evidence level: GRADE 1/B, full agreement)

A recent retrospective adult study from Denmark of 166 patients with acute cholangitis who underwent ERCP found that the presence of AP did not influence outcome independent of cholangitis [91]. Thus, studies on the timing of ERCP in adult patients with AP could be helpful in patients with biliary AP and cholangitis. Only one current retrospective study suggested that the timing of ERCP did not affect outcome, but the majority of the adult patients in the discovery (75\%) and validation cohorts (80\%) who had ERCP had the procedure within $48 \mathrm{~h}$ of admission [92]. In the adult study from Denmark, patients who underwent ERCP within $24 \mathrm{~h}$ had lower 30day mortality [91]. A prospective study of 199 consecutive adult patients with cholangitis managed by ERCP showed that a delay of more than $48 \mathrm{~h}$ was associated with a longer hospital stay and a delay of more than $72 \mathrm{~h}$ was associated with other adverse outcomes [93]. The most recent Tokyo guidelines recommend that the timing of ERCP depends on the severity of cholangitis [94,95]. Patients with severe cholangitis defined by the presence of organ failure should undergo urgent biliary drainage. Patients with moderate cholangitis, which is diagnosed when $2 / 5$ criteria (hyperbilirubinemia, high fever, leukocytosis, age 75 years or older, and hypoalbuminemia) are met should have early biliary drainage (within 24-48 h) and adult patients with mild cholangitis should have biliary drainage when supportive measures such as antibiotic therapy are not effective [96].

There are still no adult trials addressing the optimal timing of ERCP in biliary pancreatitis, and since the timing of early ERCP is not established ( $24-72 \mathrm{~h}$ ), waiting $24-48 \mathrm{~h}$ is recommended as there might be spontaneous improvement in biliary obstruction [60,61].

\section{AP-VI.3. What is the optimal timing of cholecystectomy?}

For uncomplicated biliary pancreatitis, cholecystectomy is recommended during the index admission, if possible or, if not possible, within 30 days of the first admission for mild cholelythiasis-associated AP in children. Importantly, if the cholecystectomy is not performed the patient remains at risk of another episode of AP and complications from gallstone obstruction. (Adult evidence level: GRADE 1/B, full agreement; Pediatric evidence level: GRADE 1/C, full agreement)

Two retrospective studies of early versus late cholecystectomy 
in children have been reported [97,98]. Nevertheless, pediatricians remain largely reliant on adult studies to help guide care.

A retrospective study from England of 670 cases of biliary pancreatitis with gallstones demonstrated that cholecystectomy before two weeks from the initial admission reduced the risk for readmission by $58 \%$ without increasing the operative complications [98]. A second pediatric study from the United States of 19 children found that cholecystectomy done during the index admission did not increase complications and shortened hospital stay after the surgery [97]. Two RCTs of cholecystectomy during the index admission versus delayed cholecystectomy in adults with biliary pancreatitis have been reported [99,100]. A study from Taiwan randomized 72 adult patients to early or delayed cholesystectomy [100]. It was found that early laparoscopic cholecystectomy significantly decreased the risk of readmission ( $0 \%$ vs $44 \%$, $\mathrm{p} \leq .0001$ ) and was not associated with greater operative difficulty or perioperative morbidity. A larger study from the Netherlands randomized 266 adult patients to cholecystectomy during the index admission or delayed cholecystectomy [99]. Index admission cholecystectomy reduced the rate of recurrent biliary disease (17\% vs $5 \%, \mathrm{p}=.002$ ) and had a low risk of surgical complications. In addition, 5 retrospective studies of early versus late cholecystectomy in biliary AP have been published [101-105]. Altogether over 19,000 patients were included in these studies. The definition of early cholecystectomy ranged from surgery during the index admission up to 30 days after the initial admission. All found lower rates of readmission in the early surgery group. The risk for readmission in the early surgery groups ranged from 0 to $5 \%$ and in the delayed surgery groups ranged from 13 to $45 \%$. It remains unclear if the risk for readmission increases during the 30 days after the first admission for biliary AP, which would support cholecystectomy during the index admission. Two other factors are important to consider in recommending index admission surgery. First, the prospective study from England and one of the retrospective studies showed shorter lengths of stay for adult patients who had their surgery during the index admission [100,103]. A single retrospective study showed no difference in hospital stay and the others did not analyze that metric [105]. Second, delayed cholecystectomy requires another hospital visit and increases the overall cost to the healthcare system [104].

Most of the current studies included patients with gallstone AP whereas some also included patients with biliary sludge, elevated serum transaminases or elevated bilirubin. The latter studies did not stratify their analysis and the necessity of cholecystectomy is yet to be decided in cases of ARP with biliary sludge.

In cases of severe biliary AP in adults and likely children, cholecystectomy should be delayed by 6 weeks, by which time the procedure is usually safe to perform according to clinical data [60-62,97], although a longer delay may be necessary in particular clinical circumstances.

\section{AP-VII. Treatment of complications in pediatric AP}

Due to the lack of evidence-based recommendations in children, we take into account the guidelines used in adult treatment of pancreatic necrosis and other complications of pancreatitis (infected pancreatic necrosis, pseudocysts, sterile or infected necrotic fluid collection).

There are no exact numbers for the pediatric incidence of pancreatic necrosis, but this complication is rare. In a study conducted by 7 centers, only one pediatric patient out of 380 developed necrosis [12,20,32]. Other studies found the incidence of multiple organ failure and pancreatic necrosis to be under $10 \%$ $[32,106]$, while the incidence of pseudocysts ranged 10-38\% $[32,106]$. The mortality was $2-11 \%$, mostly associated with systemic diseases [107,108].

AP-VII.1. What are the indications for intervention in pediatric necrotizing pancreatitis?

Common indications for intervention in necrotizing pancreatitis [60] include:

1. Confirmed cases of infected necrotizing pancreatitis or if strong suspicion of the same with decline in clinical status, especially with WON

2. Unconfirmed cases of infected necrotizing pancreatitis with multiple organ failure, especially with WON

3. Abdominal compartment syndrome

4. Ongoing acute bleeding

5. Bowel ischemia

6. WON causing gastric outlet syndrome, or bowel or biliary obstruction

(Adult evidence level: GRADE 1/C, full agreement)

Pediatric data is limited to case reports and series [109-111]. Based on experiences in the treatment of adults, most cases of sterile necrotizing pancreatitis can be treated without intervention. WON usually develops over more than 4 weeks following presentation with AP. A small percentage of the cases with confirmed infected necrosis, whose clinical status is stable, can be treated with only antibiotics, without the need for drainage or necrosectomy [112,113].

AP-VII.2. What is the role of fine-needle aspiration in the diagnosis of infected pnecrotic peripancreatic fluid accumulation?

Routine percutaneous FNA of peripancreatic necrotic collections is unnecessary for confirming bacterial infection, as clinical (continuous fever, elevated inflammatory markers) and imaging signs (gas in the collections) are valid predictors of infection in majority of the cases. FNA could help with the confirmation of infection, but there is also a high prevalence of false negatives (12-25\%) [112]. (Adult evidence level GRADE 1/C, full agreement)

FNA is recommended in adults in cases without improvement in clinical status weeks after the actual necrotizing pancreatitis, where unequivocal clinical and imaging signs of infected pancreatic necrosis are not present. No data are available as to whether FNA would improve outcomes by reducing the time needed for the diagnosis of infected necrosis and the initiation of antibiotic treatment. No pediatric trials are available, only case studies [114].

\section{AP-VII.3. What is the optimal timing of intervention in suspected and confirmed cases of infected pancreatic necrosis?}

Regarding the optimal timing of intervention in suspected and confirmed cases of infected pancreatic necrosis, only adult recommendations are available, relevant clinical pediatric studies have not been conducted. In confirmed or suspected infected necrotizing pancreatitis, invasive intervention (percutaneous catheter drainage, endoscopic transluminal drainage or necrosectomy) should be delayed as much as possible, but at least by 4 weeks after the initial presentation so that the collection can transform into WON. The timing of intervention should be balanced between the need to intervene and the benefits of delaying the intervention. (Adult evidence level: GRADE 1/C, full agreement)

The timing of repeat interventions (repeat percutaneous drainage, repeat endoscopic necrosectomy) should be based on clinical and imaging criteria, there are no strong recommendations on that matter in adults or children $[60,112]$. 
AP-VII.4. Which is the optimal intervention strategy in cases of suspected or confirmed infected pancreatic necrosis?

The optimal intervention strategy in cases of suspected or confirmed infected necrotizing pancreatitis is initially imagingguided percutaneous (retroperitoneal) catheter drainage or endoscopic transluminal drainage, which, if necessary, can be followed by endoscopic or surgical necrosectomy. (Adult evidence level: GRADE 1/B, full agreement)

Pediatric data from case series suggest that endoscopic transluminal drainage of WON or EUS-guided drainage using plastic or fully covered self-expanding metal stents (FCSEMS) is safe and efficacious in children [67,109-111,115]. In adult cases of infected necrotizing pancreatitis, percutaneous catheter drainage in itself can prevent $23-50 \%$ of necrosectomies [60,112,113].

\section{AP-VII.5. What are the indications for intervention in the presence of} a pseudocyst?

In the cases of an asymptomatic pancreatic pseudocysts, regardless of size, location, and/or extension observation is appropriate. When pancreatic pseudocysts are symptomatic, endoscopic intervention should be the therapy of first choice in experienced centers. (Adult evidence level: GRADE 1/C, full agreement)

RCTs on this matter have not been conducted in children. In adults, spontaneous regression is rare if the pseudocyst is bigger than $6 \mathrm{~cm}$ and persists over 4 weeks. Complicated or symptomatic pseudocysts should be treated [112]. There are reports of successful EUS-guided drainage of pseudocysts in children [106,109].

\section{Acute recurrent pancreatitis (ARP) in children}

ARP. Diagnosis and definition. It is defined by at least 2 acute attacks in the patient's lifetime without any evidence of $\mathrm{CP}$. There must be complete resolution of pain $(\geq 1$ month pain-free interval between the diagnoses of AP, or complete normalization of serum pancreatic enzyme levels (amylase and lipase), before the subsequent episode of AP is diagnosed, along with complete resolution of pain symptoms, irrespective of a specific time interval between AP episodes [3,5,116]. (GRADE 2/B, full agreement).

\section{Chronic pancreatitis (CP) IN childhood}

CP-I. Diagnosis and definition: $\mathrm{CP}$ is a progressive inflammatory process that leads to the destruction of pancreatic parenchyma and has a negative impact on pancreatic function. The diagnosis of $\mathrm{CP}$ requires characteristic histological and morphological finding with decreased pancreatic function (endocrine or exocrine) [3,5]. (GRADE 1/B, strong agreement)

\section{CP-II. Etiology of childhood onset CP}

$C P$-II.1. What kind of risk factors should be examined for $C P$ in childhood?. Genetic variations are the most common risk factors for development of pediatric CP. (GRADE 1/A, full agreement) However, other risk factors such as obstruction, autoimmune and toxic and metabolic factors also need to be examined. (GRADE 2/B, full agreement)

A review by INSPPIRE suggests that the most common risk factor for the development of $\mathrm{CP}$ is genetic alterations [27]. Other etiological factors such as obstructive (ie: pancreas divisum, gallstones, pancreaticobiliary malunion, biliary cyst, sphincter of Oddi dysfunction, annular pancreas), autoimmune or toxic/metabolic (ie. medications, smoking, alcohol) ones also can elevate the risk of developing $\mathrm{CP}$.

CP-II.2. Is there an association between $C F$ and CP?. There is an association between $\mathrm{CP}$ and $\mathrm{CF}$, therefore a sweat test should be performed to screen for $\mathrm{CF}$ as a possible etiological factor in children. (GRADE 1/A, strong agreement)

$\mathrm{CF}$ is an inflammatory disorder leading usually in utero to pancreatic fibrosis and insufficiency, but CF was excluded from the older classification systems because the special clinical features of this disorder. $2 \%$ of all patients with $\mathrm{CF}$ and $10-15 \%$ of pancreatic sufficient patients with CF suffer from ARP [38,117]. Furthermore, heterozygous carriers of CFTR mutations are overrepresented in patients with idiopathic $\mathrm{CP}$.

\section{CP-III. Treatment of acute on CP in children}

CP-III.1. How to treat acute episodes in patients with CP? The treatment for acute episodes in pediatric patients with $\mathrm{CP}$ does not differ from the management of the initial episode. Nutrition for children during an episode of acute on CP can be administered in the same way as in adult patients. (GRADE $1 / C$, full agreement)

No controlled studies exist on nutritional management during an acute episode of $\mathrm{CP}$ in the pediatric population. Early enteral nutrition should be initiated, as in adults, in order to maintain the intestinal barrier function.

CP-III.2. Should prophylactic antibiotics be administered during the exacerbation of $C P$ ?. The general use of antibiotics in children is not recommended in an acute exacerbation of CP. (Adult evidence level: GRADE 1/C, strong agreement)

There are no controlled clinical studies addressing the use of antibiotics during an acute episode of CP in childhood.

CP-IV. Imaging in CP in childhood. CP-IV.1 What kind of imaging studies are recommended in $\mathbf{C P}$ in children? Transabdominal ultrasound, EUS, CT and MRI can be used during the management for $\mathrm{CP}$ in childhood. (GRADE $1 / B$, strong agreement)

Transabdominal ultrasound is the primary imaging technique to examine $\mathrm{CP}$ in children because it is simple to perform and does not involve radiation exposure. However, there are no comparative studies on the validity of ultrasound imaging in children. The benefit of contrast-enhanced ultrasonography in children has not been evaluated. In an older study involving 273 children and adolescents between the ages of 0 and 19 years, normal standard values for pancreatic size were determined by ultrasound. The pancreatic head has a diameter of $1.0 \pm 0.4$ to $2.0 \pm 0.5 \mathrm{~cm}$ in the anterior-posterior plane (infant to young adulthood), the body of the pancreas has a diameter of $0.6 \pm 0.2$ to $1.1 \pm 0.3 \mathrm{~cm}$, and the pancreatic tail has a diameter of $1.0 \pm 0.4$ to $2.0 \pm 0.4 \mathrm{~cm}$. The main growth of the pancreas takes place in the first years and is subject to high variation. Determining the size of the pancreas, therefore, does not allow any conclusion to be drawn on the presence of $\mathrm{CP}$ [59,64].

CP-IV.2. Can EUS be performed in childhood?. Yes, EUS can be performed. This imaging examination is a valid option in children for the assessment of biliary stones. In addition, EUS is helpful during the treatment of the complications [99]. (GRADE 1/B, full agreement)

Endoscopic ultrasound is technically possible in children as early as 5 years of age and is primarily performed for diagnosing $\mathrm{CP}$ by identifying calcifications and aid in fine-needle aspiration. It has a higher sensitivity than MRCP in the diagnosis of CP [64,67,114].

CP-IV.3. When is MRCP performed in CP?. MRCP should be the first choice for the cross-sectional imaging of the pancreatic and biliary ducts. (GRADE 1/B, full agreement)

MRCP is the imaging technique to demonstrate the pancreatobiliary tree in children because the examination is only minimally invasive and does not involve radiation exposure. In children $<6$ years, it is usually only possible to perform MRCP under general anesthesia [64,118]. 
CP-IV.4. How to improve the sensitivity of MRCP?. The sensitivity of MRCP can be improved by the administration of secretin. (GRADE $1 / B$, full agreement)

One study performed in children showed that the intravenous application of secretin resulted in a better demonstration of pancreatic side branches [118].

\section{$C P-V$. Endoscopic and surgical treatment of $C P$ in childhood}

$C P$-V.1. When should ERCP be performed?. ERCP can be safely performed in children and should be reserved for interventions in experienced centres. In the presence of obstruction with concomitant signs or the presence of stones in the pancreatic duct, therapeutic intervention (sphincterotomy, stent insertion, dilation of duct strictures, or stone extraction) by ERCP could be chosen. Randomized studies in this subject are lacking in the pediatric population. (GRADE 1/C, strong agreement)

RCTs on this subject are lacking in the pediatric population. There are retrospective and prospective case series describing the diagnostic use of ERCP and EUS and their application as interventional therapy in pediatric patients with CP. ERCP-guided stent insertion, stone removal and balloon dilation have been described, as well as endoscopic ultrasound-guided drainage of symptomatic pancreatic pseudocysts. When indicated, ERCP and EUS-based interventional therapies should be tailored based on the child's size and underlying disease, availability of equipment and welltrained staff. The child's overall health (ASA classification), size and the facilities/endoscopists' preference may influence the use of conscious sedation versus general anesthesia for these procedures [114,119-121].

ERCP can safely be performed in children with a pooled complication rate of about 6\%, paralleling adults [65,66,122-127]. ERCP should not be used for diagnostic purposes in pediatric $\mathrm{CP}$, but reserved only for therapeutic interventions [128,129]. Therapeutic ERCP can provide abdominal pain relief in selected children with CP [130]. Extracorporeal shock wave lithotripsy (ESWL) has been used in conjunction with ERCP in a limited number of children with hereditary pancreatitis [65,128]. It is not known whether ESWL alone or in conjunction with ERCP would be an effective intervention for pancreatic duct stones or calcifications in pediatric $\mathrm{CP}$.

ERCP is technically difficult to perform in children $<5$ years of age. EUS is only used for special indications in children and has a higher sensitivity than MRCP in the diagnosis of CP $[65,114,118]$.

$C P-V .2$. When is surgical treatment recommended in CP? After failing conservative or endoscopic therapy, surgical intervention may be indicated in children with $\mathrm{CP}$, especially if chronic pain persists and the child has frequent recurrent attacks leading to numerous hospital stays. Prevention of pancreatic function should be the primary goal during surgical procedures. (GRADE 1/C strong agreement)

It is difficult to find EBM guidelines regarding the indication for surgery of the pancreas in pediatric patients with $\mathrm{CP}$, timing of an operation or the choice of surgical technique. Organ preservation should be the goal, but total pancreatectomy with islet autotransplant (TPIAT) should be considered as well [131,132]. EUS drainage via endoscopic cystgastrostomy has become the standard of care for drainage of large and symptomatic pancreatic pseudocysts in children $[115,133,134]$. Percutaneous or surgical drainage can be performed for a limited number of cases if endoscopic intervention has failed, unsuccessful or not available [135]. Pancreatic duct dissection, if present may require further endoscopic intervention (i.e. stent placement) or surgical approaches [136,137].

\section{$C P$-VI. Pain management in $C P$ in children}

$C P$-VI.1. What kind of pain therapy can be use in CP in childhood?. The experience with pain management in pediatric $C P$ is limited.
Endoscopic and/or surgical interventions may be needed to control pain. In general, non-narcotic analgesics should be the first line of therapy for pain, and narcotics reserved for uncontrollable pain. (GRADE 1/C, strong agreement)

Abdominal pain is a common complaint in children with $\mathrm{CP}$, affecting $~ 80 \%$ children and leading to missed school days and increased health care costs $[27,129,138]$. There is very little written about pain management in childhood-onset CP. In the INSPPIRE cohort, one-third of children with $\mathrm{CP}$ reported taking narcotics for their pain [129]. In a survey to analyze the practice of pediatric gastroenterologists who commonly treat children with $\mathrm{CP}, 75 \%$ reported providing narcotics for CP-related pain, with 50\% also prescribing centrally acting agents, such as gabapentin [139].

Pain in CP can be managed medically and/or via endoscopic or surgical approaches. The goal is to provide pain relief while preserving pancreatic exocrine and endocrine function. Medical therapies include acetaminophen, nonsteroidal anti-inflammatory drugs and narcotic analgesics. Whenever possible, non-narcotic analgesics should be the first line of therapy, with narcotics used only for uncontrollable pain. Endoscopic therapies should target duct obstruction such as duct stone removal, stent placement, stricture dilatation [140]. Surgical therapies involve drainage procedures that aim to decompress obstructed ducts, resection of strictures and removal of pancreatic stones [130,140-142]. Total pancreatectomy and islet autotransplantation may be indicated in children with $\mathrm{CP}$ and intractable pain, unresponsive to other measures [131,143].

\section{$C P$-VII. Enzyme replacement for $C P$ in childhood}

$C P$-VII.1. When and what dosage of enzyme replacement therapy is recommended?. For PERT [122] in pediatric CP, guidelines for CFinduced EPI should be used. Children less than 4 years of age should receive 1000 lipase units/kg per meal; 1000-2500 lipase units/kg per meal should be used for those $>4$ years of age; 40,000 to 50,000 units lipase/meal for children of adult size. For snacks, half of the dosing is recommended. (GRADE $1 / C$, full agreement)

If untreated, EPI can lead to fat malabsorption and nutritional deficiencies in children with $\mathrm{CP}$. The frequency of EPI in pediatric CP is not well established. In the INSPPIRE cohort, $34 \%$ of children with CP had EPI at the time of diagnosis [129]. In a Polish cohort, malnutrition was found in $25 \%$ of children with CP [144]. If a child is found to be exocrine pancreatic insufficient by fecal elastase $(<100 \mu \mathrm{g} / \mathrm{g})$ or $72 \mathrm{~h}$ fecal fat testing (coefficient of fat absorption $>15 \%$ if $<6$ months of age, $>7 \%$ for if $>6$ months of age [145], PERT is indicated. There are no guidelines on adequate dosing required for children with CP and EPI, but this is well-studied for CF. Children with $\mathrm{CF}<4$ years of age typically require 1000 lipase units $/ \mathrm{kg}$ per meal; > 4years 1000 lipase units/kg per meal; while 25,000 to 40,000 units lipase/meal are used for adults [146]. For snacks, half the dose is recommended. To prevent fibrosing colonopathy, < 10,000 units of lipase/kg per day or $<6000$ units of lipase/kg per meal should be used.

CP-VII.2. When do we have to think about PERT?. PERT in children and adolescents with $\mathrm{CP}$ should be considered when growth and weight gain are unsatisfactory or ongoing symptoms of EPI are present. (GRADE 1/C, full agreement)

Frequent voluminous stools, fatty stools, increased flatulence, excessive appetite and reduced growth rate could indicate inadequate PERT. The substitution of a pancreatic lipase preparation by a delayed-release formulation is effective and may be advantageous given poor compliance with some preparations [147].

There are no published reports about optimizing PERT in children with CP. Therefore, we recommend following CF guidelines for dose adjustments [146]. Briefly, a child with CP can be considered to have poor response to PERT, if he/she continues to have overt 
symptoms of EPI (bloating, flatus, loose and frequent stools) along with steatorrhea and/or poor growth and weight gain. PERT dosing can then be adjusted based on clinical response and/or $72 \mathrm{~h}$ fecal fat testing.

CP-VII.3. What kind of therapy could be given in cases of malabsorption even with optimized PERT?. Administration of acid suppression drugs (either a proton pump inhibitor (PPI) or H2 blockers) is recommended when severe malabsorption occurs in spite of appropriate PERT in children with CP. (GRADE 1/C, full agreement)

Increased gastrointestinal acidity has been reported in people with CF due to several factors originating from a dysfunctional CFTR, an ion channel involved in the transport of bicarbonate in pancreatic/biliary ducts, duodenal Brunner glands and others $[148,149]$. This can lead to inactivation of pancreatic enzymes in the gut and impair fat digestion. Although it is not expected that gastrointestinal $\mathrm{pH}$ will be as severely reduced in patients with $\mathrm{CF}$, gastric acid inhibition has been shown to increase the efficacy of PERT in adults [150]. There are no pediatric studies available.

\section{Future perspectives}

By writing these recommendations, not only has knowledge in the management of pediatric $\mathrm{AP}$ and $\mathrm{CP}$ been summarized but also areas that urgently require study have been identified. There is a particular lack of knowledge concerning pain management both in $\mathrm{AP}$ and $\mathrm{CP}$, as well as prognostic scoring of the severity of AP.

\section{Consensus panel}

Maisam Abu-el Haija, Frederico Alghisi, László Czakó, Alexandra Demcsák, David Fine, Tassos Grammatikopoulus, Alex Gyfropoulos, József Hamvas, Eszter Hegyi, Péter Hegyi, Sohail Husain, Johanna Laukkariren, Natalia Lásztity, Mark Lowe, Mareo Vito Marino, Katalin Márta, Dóra Mosztbacher, Natalia Nedelkopoulou, Nazar Omelchuk, Grzegorz Oracz, Ákos Pap, Andrea Párniczky, Dániel Pécsi, Ib Christian Rasmussen, Miklós Sahin-Tóth, Robert Sutton, Flóra K. Szabó, Andrea Szentesi, Alina Tantau, Marcel Tantau, Erling Tjora, Imola Török, Micheal Wilschanski, HeikoWitt

\section{Acknowledgement}

The authors are grateful to the councilors of EPC and HPSG for initiating of the PP EBM guideline.

\section{References}

[1] Morinville VD, Barmada MM, Lowe ME. Increasing incidence of acute pancreatitis at an american pediatric tertiary care center: is greater awareness among physicians responsible? Pancreas 2010;39:5-8.

[2] Hoffmeister A, Mayerle J, Beglinger C, Buchler MW, Bufler P, Dathe K, et al. English language version of the s3-consensus guidelines on chronic pancreatitis: definition, aetiology, diagnostic examinations, medical, endoscopic and surgical management of chronic pancreatitis. Z Gastroenterol 2015;53:1447-95.

[3] Morinville VD, Husain SZ, Bai H, Barth B, Alhosh R, Durie PR, et al. Definitions of pediatric pancreatitis and survey of present clinical practices. J Pediatr Gastroenterol Nutr 2012;55:261-5.

[4] Scheers I, Palermo JJ, Freedman S, Wilschanski M, Shah U, Abu-El-Haija M, et al. Autoimmune pancreatitis in children: characteristic features, diagnosis, and management. Am J Gastroenterol 2017 Oct;112(10):1604-11.

[5] Gariepy CE, Heyman MB, Lowe ME, Pohl JF, Werlin SL, Wilschanski M, et al. Causal evaluation of acute recurrent and chronic pancreatitis in children: consensus from the insppire group. J Pediatr Gastroenterol Nutr 2017;64: 95-103.

[6] Husain SZ, Morinville V, Pohl J, Abu-El-Haija M, Bellin MD, Freedman S, et al. Toxic-metabolic risk factors in pediatric pancreatitis: recommendations for diagnosis, management, and future research. J Pediatr Gastroenterol Nutr 2016;62:609-17.

[7] Parniczky A, Czako L, Dubravcsik Z, Farkas G, Hegyi P, Hritz I, et al. Pediatric pancreatitis. Evidence based management guidelines of the Hungarian pancreatic study group. Orv Hetil 2015;156:308-25.

8] Coffey MJ, Nightingale S, Ooi CY. Diagnosing acute pancreatitis in children: what is the diagnostic yield and concordance for serum pancreatic enzymes and imaging within 96 h of presentation? Pancreatology 2014;14:251-6.

[9] Werlin SL, Kugathasan S, Frautschy BC. Pancreatitis in children. J Pediatr Gastroenterol Nutr 2003:37:591-5.

[10] Bai HX, Lowe ME, Husain SZ. What have we learned about acute pancreatitis in children? J Pediatr Gastroenterol Nutr 2011;52:262-70.

[11] Berney T, Belli D, Bugmann P, Beghetti M, Morel P, LeCoultre C. Influence of severe underlying pathology and hypovolemic shock on the development of acute pancreatitis in children. J Pediatr Surg 1996;31:1256-61.

[12] Park AJ, Latif SU, Ahmad MU, Bultron G, Orabi AI, Bhandari V, et al. A comparison of presentation and management trends in acute pancreatitis between infants/toddlers and older children. J Pediatr Gastroenterol Nutr 2010;51:167-70.

[13] Tiao MM, Chuang JH, Ko SF, Kuo HW, Liang CD, Chen CL. Pancreatitis in children: clinical analysis of 61 cases in southern taiwan. Chang Gung Med J 2002; $25: 162-8$.

[14] Ziegler DW, Long JA, Philippart AI, Klein MD. Pancreatitis in childhood. Experience with 49 patients. Ann Surg 1988;207:257-61.

[15] Jordan SC, Ament ME. Pancreatitis in children and adolescents. J Pediatr 1977;91:211-6.

[16] Nydegger A, Heine RG, Ranuh R, Gegati-Levy R, Crameri J, Oliver MR. Changing incidence of acute pancreatitis: 10-year experience at the royal children's hospital, melbourne. J Gastroenterol Hepatol 2007;22:1313-6.

[17] Kandula L, Lowe ME. Etiology and outcome of acute pancreatitis in infants and toddlers. J Pediatr 2008;152:106-10. 110 e101.

[18] Husain SZ, Srinath AI. What's unique about acute pancreatitis in children: risk factors, diagnosis and management. Nat Rev Gastroenterol Hepato 2017:14:366-72.

[19] Ma MH, Bai HX, Park AJ, Latif SU, Mistry PK, Pashankar D, et al. Risk factors associated with biliary pancreatitis in children. J Pediatr Gastroenterol Nutr 2012;54:651-6.

[20] Abu-El-Haija M, Lin TK, Palermo J. Update to the management of pediatric acute pancreatitis: highlighting areas in need of research. J Pediatr Gastroenterol Nutr 2014;58:689-93.

[21] Choi BH, Lim YJ, Yoon CH, Kim EA, Park YS, Kim KM. Acute pancreatitis associated with biliary disease in children. J Gastroenterol Hepatol 2003;18: $915-21$.

[22] Coffey MJ, Nightingale S, Ooi CY. Predicting a biliary aetiology in paediatric acute pancreatitis. Arch Dis Child 2013:98:965-9.

[23] Fogel EL, Toth TG, Lehman GA, DiMagno MJ, DiMagno EP. Does endoscopic therapy favorably affect the outcome of patients who have recurrent acute pancreatitis and pancreas divisum? Pancreas 2007;34:21-45.

[24] Bertin C, Pelletier AL, Vullierme MP, Bienvenu T, Rebours V, Hentic O, et al. Pancreas divisum is not a cause of pancreatitis by itself but acts as a partner of genetic mutations. Am J Gastroenterol 2012;107:311-7.

[25] Bai HX, Ma MH, Orabi AI, Park A, Latif SU, Bhandari V, et al. Novel characterization of drug-associated pancreatitis in children. J Pediatr Gastroentero Nutr 2011;53:423-8.

[26] Joergensen M, Brusgaard K, Cruger DG, Gerdes AM. Schaffalitzky de Muckadell OB: incidence, etiology and prognosis of first-time acute pancreatitis in young patients: a population-based cohort study. Pancreatology 2010;10: 453-61.

[27] Kumar S, Ooi CY, Werlin S, Abu-El-Haija M, Barth B, Bellin MD, et al. Risk factors associated with pediatric acute recurrent and chronic pancreatitis: lessons from insppire. JAMA Pediatr 2016;170:562-9.

[28] DeBanto JR, Goday PS, Pedroso MR, Iftikhar R, Fazel A, Nayyar S, et al. Acute pancreatitis in children. Am J Gastroenterol 2002;97:1726-31.

[29] Srinath AI, Gupta N, Husain SZ. Probing the association of pancreatitis in inflammatory bowel disease. Inflamm Bowel Dis 2016;22:465-75.

[30] Hart PA, Levy MJ, Smyrk TC, Takahashi N, Abu Dayyeh BK, Clain JE, et al. Clinical profiles and outcomes in idiopathic duct-centric chronic pancreatitis (type 2 autoimmune pancreatitis): the mayo clinic experience. Gut 2016;65: 1702-9.

[31] Sadr-Azodi O, Sanders DS, Murray JA, Ludvigsson JF. Patients with celiac disease have an increased risk for pancreatitis. Clin Gastroenterol Hepatol 2012;10, e1133. 1136-1142.

[32] Lowe ME, Greer JB. Pancreatitis in children and adolescents. Curr Gastroenterol Rep 2008;10:128-35.

[33] Patel RS, Johlin Jr FC, Murray JA. Celiac disease and recurrent pancreatitis Gastrointest Endosc 1999;50:823-7.

[34] Whitcomb DC, Gorry MC, Preston RA, Furey W, Sossenheimer MJ, Ulrich CD et al. Hereditary pancreatitis is caused by a mutation in the cationic trypsinogen gene. Nat Genet 1996;14:141-5.

[35] Witt H, Luck W, Hennies HC, Classen M, Kage A, Lass U, et al. Mutations in the gene encoding the serine protease inhibitor, kazal type 1 are associated with chronic pancreatitis. Nat Genet 2000;25:213-6.

[36] Rosendahl J, Witt H, Szmola R, Bhatia E, Ozsvari B, Landt O, et al. Chymotrypsin c (ctrc) variants that diminish activity or secretion are associated with chronic pancreatitis. Nat Genet 2008;40:78-82.

[37] Witt H, Beer S, Rosendahl J, Chen JM, Chandak GR, Masamune A, et al. Variants in cpa1 are strongly associated with early onset chronic pancreatitis. Nat Genet 2013;45:1216-20.

[38] Rosendahl J, Landt O, Bernadova J, Kovacs P, Teich N, Bodeker H, et al. Cftr 
spink1, ctrc and prss1 variants in chronic pancreatitis: is the role of mutated cftr overestimated? Gut 2013;62:582-92.

[39] Ooi CY, Dorfman R, Cipolli M, Gonska T, Castellani C, Keenan K, et al. Type of cftr mutation determines risk of pancreatitis in patients with cystic fibrosis. Gastroenterology 2011;140:153-61.

[40] Fjeld K, Weiss FU, Lasher D, Rosendahl J, Chen JM, Johansson BB, et al. A recombined allele of the lipase gene cel and its pseudogene celp confers susceptibility to chronic pancreatitis. Nat Genet 2015;47:518-22.

[41] Fagenholz PJ, Fernandez-del Castillo C, Harris NS, Pelletier AJ, Camargo Jr CA Direct medical costs of acute pancreatitis hospitalizations in the United States. Pancreas 2007;35:302-7.

[42] Banks PA, Bollen TL, Dervenis C, Gooszen HG, Johnson CD, Sarr MG, et al. Classification of acute pancreatitis-2012: revision of the atlanta classification and definitions by international consensus. Gut 2013;62:102-11.

[43] Ranson JH. Acute pancreatitis. Curr Probl Surg 1979;16:1-84.

[44] Imrie CW, Benjamin IS, Ferguson JC, McKay AJ, Mackenzie I, O'Neill J, et al. A single-centre double-blind trial of trasylol therapy in primary acute pancreatitis. Br J Surg 1978;65:337-41.

[45] Blamey SL, Imrie CW, O'Neill J, Gilmour WH, Carter DC. Prognostic factors in acute pancreatitis. Gut 1984;25:1340-6.

[46] Wu BU, Johannes RS, Sun X, Tabak Y, Conwell DL, Banks PA. The early prediction of mortality in acute pancreatitis: a large population-based study. Gut 2008;57:1698-703.

[47] Knaus WA, Draper EA, Wagner DP, Zimmerman JE. Apache ii: a severity of disease classification system. Crit Care Med 1985;13:818-29.

[48] Larvin M, McMahon MJ. Apache-ii score for assessment and monitoring of acute pancreatitis. Lancet 1989;2:201-5.

[49] Steinberg WM. Predictors of severity of acute pancreatitis. Gastroenterol Clin North Am 1990;19:849-61.

[50] Balthazar EJ, Ranson JH, Naidich DP, Megibow AJ, Caccavale R, Cooper MM. Acute pancreatitis: prognostic value of ct. Radiology 1985;156:767-72.

[51] Fabre A, Petit P, Gaudart J, Mas E, Vial J, Olives JP, et al. Severity scores in children with acute pancreatitis. J Pediatr Gastroenterol Nutr 2012;55 266-7.

[52] Bierma MJ, Coffey MJ, Nightingale S, van Rheenen PF, Ooi CY. Predicting severe acute pancreatitis in children based on serum lipase and calcium: a multicentre retrospective cohort study. Pancreatology 2016;16:529-34.

[53] Fabre A, Boulogne O, Gaudart J, Mas E, Olives JP, Sarles J. Evaluation of serum lipase as predictor of severity of acute pancreatitis in children. J Pediatr Gastroenterol Nutr 2014;58:e41-42.

[54] Szabo FK, Hornung L, Oparaji JA, Alhosh R, Husain SZ, Liu QY, et al. A prognostic tool to predict severe acute pancreatitis in pediatrics. Pancreatology 2016;16:358-64.

[55] Lankisch PG, Burchard-Reckert S, Lehnick D. Underestimation of acute pancreatitis: patients with only a small increase in amylase/lipase levels can also have or develop severe acute pancreatitis. Gut 1999;44:542-4.

[56] Coffey MJ, Nightingale S, Ooi CY. Serum lipase as an early predictor of severity in pediatric acute pancreatitis. J Pediatr Gastroenterol Nutr 2013;56: $602-8$.

[57] Uc A. Predicting the severity of pediatric acute pancreatitis: are we there yet? J Pediatr Gastroenterol Nutr 2013;56:584-5.

[58] Suzuki M, Saito N, Naritaka N, Nakano S, Minowa K, Honda Y, et al. Scoring system for the prediction of severe acute pancreatitis in children. Pediatr Int 2015;57:113-8.

[59] Siegel MJ, Martin KW, Worthington JL. Normal and abnormal pancreas in children: us studies. Radiology 1987;165:15-8.

[60] Iap/apa evidence-based guidelines for the management of acute pancreatitis Pancreatology 2013;13:e1-15.

[61] Aga institute medical position statement on acute pancreatitis. Gastroenterology 2007;132:2019-21.

[62] Banks PA, Freeman ML. Practice guidelines in acute pancreatitis. Am J Gastroenterol 2006;101:2379-400.

[63] Rescorla FJ, Plumley DA, Sherman S, Scherer 3rd LR, West KW, Grosfeld JL. The efficacy of early ercp in pediatric pancreatic trauma. J Pediatr Surg 1995;30:336-40.

[64] Darge K, Anupindi S. Pancreatitis and the role of us, mrcp and ercp. Pediatr Radiol 2009;39(Suppl 2):S153-7.

[65] Agarwal J, Nageshwar Reddy D, Talukdar R, Lakhtakia S, Ramchandani M, Tandan M, et al. Ercp in the management of pancreatic diseases in children. Gastrointest Endosc 2014;79:271-8.

[66] Giefer MJ, Kozarek RA. Technical outcomes and complications of pediatric ercp. Surg Endosc 2015;29:3543-50.

[67] Varadarajulu S, Wilcox CM, Eloubeidi MA. Impact of eus in the evaluation of pancreaticobiliary disorders in children. Gastrointest Endosc 2005;62: 239-44.

[68] Tipnis NA, Dua KS, Werlin SL. A retrospective assessment of magnetic resonance cholangiopancreatography in children. J Pediatr Gastroenterol Nutr 2008;46:59-64.

[69] Wu BU, Hwang JQ, Gardner TH, Repas K, Delee R, Yu S, et al. Lactated ringer's solution reduces systemic inflammation compared with saline in patients with acute pancreatitis. Clin Gastroenterol Hepatol 2011;9, e711. 710-717.

[70] Du XJ, Hu WM, Xia Q, Huang ZW, Chen GY, Jin XD, et al. Hydroxyethyl starch resuscitation reduces the risk of intra-abdominal hypertension in severe acute pancreatitis. Pancreas 2011;40:1220-5.

[71] Mao EQ, Tang YQ, Fei J, Qin S, Wu J, Li L, et al. Fluid therapy for severe acute pancreatitis in acute response stage. Chin Med J (Engl) 2009;122:169-73.

[72] Buxbaum J, Yan A, Yeh K, Lane C, Nguyen N, Laine L. Aggressive hydration with lactated ringer's solution reduces pancreatitis after endoscopic retrograde cholangiopancreatography. Clin Gastroenterol Hepatol 2014;12, e301. 303-307.

[73] Lipinski M, Rydzewska-Rosolowska A, Rydzewski A, Rydzewska G. Fluid resuscitation in acute pancreatitis: normal saline or lactated ringer's solution? World J Gastroenterol 2015;21:9367-72.

[74] Szabo FK, Fei L, Cruz LA, Abu-El-Haija M. Early enteral nutrition and aggressive fluid resuscitation are associated with improved clinical outcomes in acute pancreatitis. J Pediatr 2015;167, e391. 397-402.

[75] Buxbaum JL, Quezada M, Da B, Jani N, Lane C, Mwengela D, et al. Early aggressive hydration hastens clinical improvement in mild acute pancreatitis. Am J Gastroenterol 2017;112:797-803.

[76] Organization WH. Persisting pain in children package: who guidelines on the pharmacological treatment of persisting pain in children with medical illnesses. 2012.

[77] Petrov MS, van Santvoort HC, Besselink MG, Cirkel GA, Brink MA, Gooszen HG. Oral refeeding after onset of acute pancreatitis: a review of literature. Am J Gastroenterol 2007;102:2079-84. quiz 2085.

[78] Eckerwall GE, Tingstedt BB, Bergenzaun PE, Andersson RG. Immediate oral feeding in patients with mild acute pancreatitis is safe and may accelerate recovery-a randomized clinical study. Clin Nutr 2007;26:758-63.

[79] Moraes JM, Felga GE, Chebli LA, Franco MB, Gomes CA, Gaburri PD, et al. A full solid diet as the initial meal in mild acute pancreatitis is safe and result in a shorter length of hospitalization: results from a prospective, randomized, controlled, double-blind clinical trial. J Clin Gastroenterol 2010;44: $517-22$.

[80] Abu-El-Haija M, Wilhelm R, Heinzman C, Siqueira BN, Zou Y, Fei L, et al. Early enteral nutrition in children with acute pancreatitis. J Pediatr Gastroenterol Nutr 2016;62:453-6.

[81] Ellery KM, Kumar S, Crandall W, Gariepy C. The benefits of early oral nutrition in mild acute pancreatitis. J Pediatr 2017;191:164-9.

[82] Zhu Y, Yin H, Zhang R, Ye X, Wei J. Nasogastric nutrition versus nasojejunal nutrition in patients with severe acute pancreatitis: a meta-analysis of randomized controlled trials. Gastroenterol Res Pract 2016;2016, 6430632.

[83] Nally DM, Kelly EG, Clarke M, Ridgway P. Nasogastric nutrition is efficacious in severe acute pancreatitis: a systematic review and meta-analysis. Br J Nutr 2014;112:1769-78.

[84] Chang YS, Fu HQ Xiao YM, Liu JC. Nasogastric or nasojejunal feeding in predicted severe acute pancreatitis: a meta-analysis. Crit Care 2013:17:R118.

[85] Singh N, Sharma B, Sharma M, Sachdev V, Bhardwaj P, Mani K, et al. Evaluation of early enteral feeding through nasogastric and nasojejunal tube in severe acute pancreatitis: a noninferiority randomized controlled trial. Pancreas 2012;41:153-9.

[86] Kumar A, Singh N, Prakash S, Saraya A, Joshi YK. Early enteral nutrition in severe acute pancreatitis: a prospective randomized controlled trial comparing nasojejunal and nasogastric routes. J Clin Gastroenterol 2006;40: 431-4.

[87] Eatock FC, Chong P, Menezes N, Murray L, McKay CJ, Carter CR, et al. A randomized study of early nasogastric versus nasojejunal feeding in severe acute pancreatitis. Am J Gastroenterol 2005;100:432-9.

[88] Kumar S, Gariepy CE. Nutrition and acute pancreatitis: review of the literature and pediatric perspectives. Curr Gastroenterol Rep 2013;15:338.

[89] McClave SA, Chang WK, Dhaliwal R, Heyland DK. Nutrition support in acute pancreatitis: a systematic review of the literature. JPEN - J Parenter Enter Nutr 2006;30:143-56.

[90] Tse F, Yuan Y. Early routine endoscopic retrograde cholangiopancreatography strategy versus early conservative management strategy in acute gallstone pancreatitis. Cochrane Database Syst Rev 2012, CD009779.

[91] Tan M, Schaffalitzky de Muckadell OB, Laursen SB. Association between early ercp and mortality in patients with acute cholangitis. Gastrointest Endosc 2018 Jan;87(1):185-92.

[92] Schwed AC, Boggs MM, Pham XD, Watanabe DM, Bermudez MC, Kaji AH, et al. Association of admission laboratory values and the timing of endoscopic retrograde cholangiopancreatography with clinical outcomes in acute cholangitis. JAMA Surg 2016;151:1039-45.

[93] Hou LA, Laine L, Motamedi N, Sahakian A, Lane C, Buxbaum J. Optimal timing of endoscopic retrograde cholangiopancreatography in acute cholangitis. J Clin Gastroenterol 2017;51:534-8.

[94] Takada T, Strasberg SM, Solomkin JS, Pitt HA, Gomi H, Yoshida M, et al. Tg13: updated tokyo guidelines for the management of acute cholangitis and cholecystitis. J Hepatobiliary Pancreat Sci 2013;20:1-7.

[95] Tsuchiya T, Sofuni A, Tsuji S, Mukai S, Matsunami Y, Nagakawa Y, et al. Endoscopic management of acute cholangitis according to the $\operatorname{tg} 13$. Dig Endosc 2017;2(29 Suppl):94-9.

[96] Kiriyama S, Takada T, Strasberg SM, Solomkin JS, Mayumi T, Pitt HA, et al. Tg13 guidelines for diagnosis and severity grading of acute cholangitis (with videos). J Hepatobiliary Pancreat Sci 2013;20:24-34.

[97] Lin TK, Palermo JJ, Nathan JD, Tiao GM, Hornung LN, Fei L, et al. Timing of cholecystectomy in children with biliary pancreatitis. J Pediatr Gastroenterol Nutr 2016;62:118-21.

[98] Wilkinson DJ, Mehta N, Hennessey I, Edgar D, Kenny SE. Early cholecystectomy in children with gallstone pancreatitis reduces readmissions. J Pediatr Surg 2015;50:1293-6. 
[99] da Costa DW, Bouwense SA, Schepers NJ, Besselink MG, van Santvoort HC, van Brunschot S, et al. Same-admission versus interval cholecystectomy for mild gallstone pancreatitis (poncho): a multicentre randomised controlled trial. Lancet 2015;386:1261-8.

[100] Jee SL, Jarmin R, Lim KF, Raman K. Outcomes of early versus delayed cholecystectomy in patients with mild to moderate acute biliary pancreatitis: a randomized prospective study. Asian J Surg 2018 Jan;41(1):47-54.

[101] Shim JM, Kim J. Cross-national differences in the holistic use of traditional east asian medicine in east asia. Health Promot Int 2016 Dec 23 . pii: daw089.

[102] Kim SB, Kim TN, Chung HH, Kim KH. Small gallstone size and delayed cholecystectomy increase the risk of recurrent pancreatobiliary complications after resolved acute biliary pancreatitis. Dig Dis Sci 2017;62:777-83.

[103] Borreca D, Bona A, Bellomo MP, Borasi A. P DEP: timing of cholecystectomy in acute biliary pancreatitis: is it still reasonable to wait? Minerva Chir 2016;71:31-7

[104] Boshnaq MH, Merali N, El Abbassy IH, Eldesouky SA, Rabie MA. Financial burden secondary to delay in cholecystectomy following mild biliary pancreatitis. J Invest Surg 2017;30:170-6.

[105] Degrate L, Bernasconi DP, Meroni P, Garancini M, Macchini D, Romano F, et al. Mild acute biliary pancreatitis: the timing of cholecystectomy should not exceed index admission. Minerva Chir 2017 Oct;72(5):383-90.

[106] Bolia R, Srivastava A, Yachha SK, Poddar U, Kumar S. Prevalence, natural history, and outcome of acute fluid collection and pseudocyst in children with acute pancreatitis. J Pediatr Gastroenterol Nutr 2015;61:451-5.

[107] Pant C, Deshpande A, Olyaee M, Anderson MP, Bitar A, Steele MI, et al. Epidemiology of acute pancreatitis in hospitalized children in the United States from 2000-2009. PLoS One 2014;9, e95552.

[108] Goday PS, Wakeham M, Kuhn EM, Collins MM, Werlin SL. Acute pancreatitis in the pediatric intensive care unit. J Pediatr Gastroenterol Nutr 2015;61: $108-12$.

[109] Nabi Z, Lakhtakia S, Basha J, Chavan R, Gupta R, Ramchandani M, et al. Endoscopic drainage of pancreatic fluid collections: long-term outcomes in children. Dig Endosc 2017 Nov;29(7):790-7.

[110] Trikudanathan G, Arain M, Mallery S, Freeman M, Attam R. Endoscopic necrosectomy in children. J Pediatr Gastroenterol Nutr 2014;59:270-3.

[111] Nabi Z, Lakhtakia S, Basha J, Chavan R, Ramchandani M, Gupta R, et al Endoscopic ultrasound-guided drainage of walled-off necrosis in children with fully covered self-expanding metal stents. J Pediatr Gastroenterol Nutr 2017;64:592-7.

[112] Tenner S, Baillie J, DeWitt J, Vege SS. American college of gastroenterology guideline: management of acute pancreatitis. Am J Gastroenterol 2013;108, 1416. $1400-1415$.

[113] Mukai S, Itoi T, Sofuni A, Itokawa F, Kurihara T, Tsuchiya T, et al. Expanding endoscopic interventions for pancreatic pseudocyst and walled-off necrosis. J Gastroenterol 2015;50:211-20.

[114] Gordon K, Conway J, Evans J, Petty J, Fortunato JE, Mishra G. Eus and eusguided interventions alter clinical management in children with digestive diseases. J Pediatr Gastroenterol Nutr 2016;63:242-6.

[115] Jazrawi SF, Barth BA, Sreenarasimhaiah J. Efficacy of endoscopic ultrasoundguided drainage of pancreatic pseudocysts in a pediatric population. Dig Dis Sci 2011:56:902-8.

[116] Srinath AI, Lowe ME. Pediatric pancreatitis. Pediatr Rev 2013;34:79-90.

[117] Durno C, Corey M, Zielenski J, Tullis E, Tsui LC, Durie P. Genotype and phenotype correlations in patients with cystic fibrosis and pancreatitis. Gastroenterology 2002;123:1857-64.

[118] Manfredi R, Lucidi V, Gui B, Brizi MG, Vecchioli A, Maresca G, et al. Idiopathic chronic pancreatitis in children: Mr cholangiopancreatography after secretin administration. Radiology 2002;224:675-82.

[119] Attila T, Adler DG, Hilden K, Faigel DO. Eus in pediatric patients. Gastrointest Endosc 2009;70:892-8.

[120] Hsu RK, Draganov P, Leung JW, Tarnasky PR, Yu AS, Hawes RH, et al. Therapeutic ercp in the management of pancreatitis in children. Gastrointest Endosc 2000;51:396-400.

[121] Troendle DM, Fishman DS, Barth BA, Giefer MJ, Lin TK, Liu QY, et al. Therapeutic endoscopic retrograde cholangiopancreatography in pediatric patients with acute recurrent and chronic pancreatitis: data from the insppire (international study group of pediatric pancreatitis: in search for a cure) study. Pancreas 2017;46:764-9.

[122] Oracz G, Pertkiewicz J, Kierkus J, Dadalski M, Socha J, Ryzko J. Efficiency of pancreatic duct stenting therapy in children with chronic pancreatitis. Gastrointest Endosc 2014;80:1022-9.

[123] Jang JY, Yoon CH, Kim KM. Endoscopic retrograde cholangiopancreatography in pancreatic and biliary tract disease in Korean children. World J Gastroenterol 2010;16:490-5.

[124] Andriulli A, Loperfido S, Napolitano G, Niro G, Valvano MR, Spirito F, et al. Incidence rates of post-ercp complications: a systematic survey of prospective studies. Am J Gastroenterol 2007;102:1781-8.

[125] Cotton PB, Garrow DA, Gallagher J, Romagnuolo J. Risk factors for complications after ercp: a multivariate analysis of 11,497 procedures over 12 years. Gastrointest Endosc 2009;70:80-8.
[126] Barthet M, Lesavre N, Desjeux A, Gasmi M, Berthezene P, Berdah S, et al. Complications of endoscopic sphincterotomy: results from a single tertiary referral center. Endoscopy 2002;34:991-7.

[127] Masci E, Toti G, Mariani A, Curioni S, Lomazzi A, Dinelli M, et al. Complications of diagnostic and therapeutic ercp: a prospective multicenter study. Am J Gastroenterol 2001;96:417-23.

[128] Oracz G, Kolodziejczyk E, Sobczynska-Tomaszewska A, Wejnarska K, Dadalski M, Grabarczyk AM, et al. The clinical course of hereditary pancreatitis in children - a comprehensive analysis of 41 cases. Pancreatology 2016;16:535-41.

[129] Schwarzenberg SJ, Bellin M, Husain SZ, Ahuja M, Barth B, Davis H, et al Pediatric chronic pancreatitis is associated with genetic risk factors and substantial disease burden. J Pediatr 2015;166, e891. 890-896.

[130] Li ZS, Wang W, Liao Z, Zou DW, Jin ZD, Chen J, et al. A long-term follow-up study on endoscopic management of children and adolescents with chronic pancreatitis. Am J Gastroenterol 2010;105:1884-92.

[131] Bellin MD, Forlenza GP, Majumder K, Berger M, Freeman ML, Beilman GJ et al. Total pancreatectomy with islet autotransplantation resolves pain in young children with severe chronic pancreatitis. J Pediatr Gastroenterol Nutr 2017:64:440-5.

[132] Bellin MD, Schwarzenberg SJ, Cook M, Sutherland DE, Chinnakotla S. Pediatric autologous islet transplantation. Curr Diabetes Rep 2015;15:67.

[133] Scheers I, Ergun M, Aouattah T, Piessevaux H, Borbath I, Stephenne X, et al. Diagnostic and therapeutic roles of endoscopic ultrasound in pediatric pancreaticobiliary disorders. J Pediatr Gastroenterol Nutr 2015;61:238-47.

[134] Sharma SS, Maharshi S. Endoscopic management of pancreatic pseudocyst in children-a long-term follow-up. J Pediatr Surg 2008:43:1636-9.

[135] Russell KW, Barnhart DC, Madden J, Leeflang E, Jackson WD, Feola GP, et al Non-operative treatment versus percutaneous drainage of pancreatic pseudocysts in children. Pediatr Surg Int 2013;29:305-10.

[136] Krige JE, Kotze UK, Navsaria PH, Nicol AJ. Endoscopic and operative treatment of delayed complications after pancreatic trauma: an analysis of 27 civilians treated in an academic level 1 trauma centre. Pancreatology 2015;15:563-9.

[137] Snajdauf J, Rygl M, Kalousova J, Kucera A, Petru O, Pycha K, et al. Surgica management of major pancreatic injury in children. Eur J Pediatr Surg 2007; 17:317-21.

[138] Ting J, Wilson L, Schwarzenberg SJ, Himes R, Barth B, Bellin MD, et al. Direct costs of acute recurrent and chronic pancreatitis in children in the insppire registry. J Pediatr Gastroenterol Nutr 2016;62:443-9.

[139] Morinville VD, Lowe ME, Ahuja M, Barth B, Bellin MD, Davis H, et al. Design and implementation of insppire. J Pediatr Gastroenterol Nutr 2014;59: 360-4.

[140] Chowdhury SD, Chacko A, Ramakrishna BS, Dutta AK, Augustine J, Koshy AK, et al. Clinical profile and outcome of chronic pancreatitis in children. Indian Pediatr 2013;50:1016-9.

[141] Sacco Casamassima MG, Goldstein SD, Yang J, Gause CD, Abdullah F, Meoded A, et al. The impact of surgical strategies on outcomes for pediatric chronic pancreatitis. Pediatr Surg Int 2017;33:75-83.

[142] Laje P, Adzick NS. Modified puestow procedure for the management of chronic pancreatitis in children. J Pediatr Surg 2013;48:2271-5.

[143] Chinnakotla S, Bellin MD, Schwarzenberg SJ, Radosevich DM, Cook M, Dunn TB, et al. Total pancreatectomy and islet autotransplantation in children for chronic pancreatitis: indication, surgical techniques, postoperative management, and long-term outcomes. Ann Surg 2014;260:56-64.

[144] Kolodziejczyk E, Wejnarska K, Dadalski M, Kierkus J, Ryzko J, Oracz G. The nutritional status and factors contributing to malnutrition in children with chronic pancreatitis. Pancreatology 2014;14:275-9.

[145] Fomon SJ, Ziegler EE, Thomas LN, Jensen RL, Filer Jr LJ. Excretion of fat by normal full-term infants fed various milks and formulas. Am J Clin Nutr 1970;23:1299-313.

[146] Borowitz DS, Grand RJ, Durie PR. Use of pancreatic enzyme supplements for patients with cystic fibrosis in the context of fibrosing colonopathy. Consensus committee. J Pediatr 1995; 127:681-4.

[147] Stallings VA, Stark LJ, Robinson KA, Feranchak AP, Quinton $\mathrm{H}$. Evidencebased practice recommendations for nutrition-related management of children and adults with cystic fibrosis and pancreatic insufficiency: results of a systematic review. J Am Diet Assoc 2008;108:832-9.

[148] Gelfond D, Ma C, Semler J, Borowitz D. Intestinal ph and gastrointestina transit profiles in cystic fibrosis patients measured by wireless motility capsule. Dig Dis Sci 2013;58:2275-81.

149] Gelfond D, Heltshe S, Ma C, Rowe SM, Frederick C, Uluer A, et al. Impact of cftr modulation on intestinal ph, motility, and clinical outcomes in patients with cystic fibrosis and the g551d mutation. Clin Transl Gastroenterol 2017;8:e81.

[150] Vecht J, Symersky T, Lamers CB, Masclee AA. Efficacy of lower than standard doses of pancreatic enzyme supplementation therapy during acid inhibition in patients with pancreatic exocrine insufficiency. J Clin Gastroenterol 2006:40:721-5 